\title{
Carcinoma intra-epitelial del cervix uterino
}

\author{
Doctores Guillermo López_Escobar, Luis A. Urdaneta, Enrique \\ Darnalt, Germán Jordán, Hernando Osorio, Hugo Quijano, Jaime \\ Salazar.
}

Ponencia presentada por la Delegación de Bogotá (Instituto Nacional de Cancerología) a la III Convención Nacional de Ginecología y Obstetricia, reunida en Ibagué en diciembre de 1957.

\section{INTRODUCCION}

En las estadísticas de tumores malignos de la mayoría de los países, el carcinoma del cervix ocupa el primer sitio en frecuencia y en nuestro medio como peculiaridad colombiana su frecuencia es solamente superada por el cáncer de la piel. Es por esto que, con justa razón, fue escogido como uno de los temas centrales de la Convención pasada y ahora en su forma intraepitelial es motivo de ponencia en esta reunión de Ibagué. La importancia de la forma intra-epitelial, se hace más palpable aún si aceptamos que su tratamiento en este estado 0, estado inicial, debe darnos un ciento por ciento de curaciones, cosa que no sucede cuando el carcinoma es francamente invasor (1).

Recordemos que la forma intra-epitelial del carcinoma del cervix constituye aún motivo de intensas investigaciones, pues sus diversas modalidades de evolución, criterio histológico, tratamiento, etc., no están completamente definidas ni aceptadas por todas las autoridades en la materia. Recordemos también la incertidumbre y la estrecha relación que existe entre el carcinoma cervical y todo aquel gran grupo de lesiones de los epitelios del cervix catalogados en forma general como lesiones distróficas cervicales y cuán notable seria el papel de profilaxis que desempeñaría el ginecólogo el día en que pudiera determinar con certeza cuáles de estas lesiones distróficas son verdaderamente pre-malignas o pre-cancerosas; y cuáles cambios histoló- 
gicos o histoquímicos son criterios ciertos de que existe un verdadero carcinoma intraepitelial.

Por las anteriores razones hemos creído conveniente incluir como primera parte de esta ponencia el resumen publicado recientemente por uno de nosotros (1-A), fruto del estudio de más de seiscientas biopsias de supuestas lesiones distróficas cervicales, realizado en los Laboratorios de Anatomía Patológica del Instituto Nacional de Cancerología, y en el que se investiga también la carga en glucógeno de las lesiones distróficas y el carcinoma in-situ y su valoración en el diagnớstico histopatológico, teniendo en cuenta que la ausencia o desaparición del glucógeno puede ser un indicio de malignidad.

La segunda parte estará dedicada a la discusión de una serie de casos de carcinoma cervical, divididos en dos grupos:

a) Verdaderos carcinomas intra-epiteliales comprobados hasta la saciedad por histologia, conducta, evolución, etc., y

b) Un grupo de casos invasivos de los cuales hemos escogido cuatro para comentar por sus enseñanzas desde el punto de vista de histología, conducta, etc.

Por último, la tercera parte la constituyen unos breves comentarios y conclusiones relacionados con diagnóstico, conducta del carcinoma intra-epitelial.

\section{LESIONES DISTROFICAS Y CARCINOMA IN-SITU DEL CERVIX} El epitelio del cuello uterino (4-5-9)

Como es bien sabido el epitelio del cuello uterino es de dos tipos: escamoso estratificado y epitelio glandular.

La "pars vaginalis" que hace protrusión dentro de la vagina está cubierta por un epitelio esencialmente similar al epitelio estratificado de la vagina, aunque las papilas subepiteliales son mucho menos marcadas y pueden estar ausentes. Este epitelio se caracteriza por un conjunto ordenado de capas. La más profunda: capa basal o stratum germinativum o stratum cylindricum está compuesta de células con poco citoplasma y núcleos hipercromáticos alargados, en forma de empalizada, perpendiculares al estroma subyacente. Por encima de esta capa, en los estratos siguientes, a medida que las células se hacen más superficiales aumenta su citoplasma, se cargan de glucógeno, se aplanan; el núcleo disminuye de tamaño, se horizontaliza, se hace picnótico y aún desaparece en las capas superficiales; los 
puentes intercelulares visibles en las capas profundas desaparecen o se hacen menos visibles. La capa superficial o zona de descamación similar al stratum corneum de la piel, normalmente no muestra cornificación a no ser que el cuello uterino esté expuesto como resultado de un prolapso, al ambiente exterior, caso en el cual se cornifica volviéndose casi como la piel.

El epitelio del endocervix de características completamente diferentes es cilíndrico, uniestratificado, sin cilias y con glándulas en tridente. Estas glándulas no se encuentran en el cuello uterino del feto, pero ya a los cinco años se encuentra un esbozo de ellas, como lo pudimos comprobar en los cortes histológicos del cuello uterino de una niña de esta edad (figuras números I, I-A y I-B).

El epitelio pavimentoso estratificado del cervix se extiende hasta cerca del orificio externo, pero las variaciones individuales a este respecto son notorias, siendo la línea de demarcación frecuentemente un poco más distal o más proximal al orificio. La transición entre uno y otro epitelio es por lo general bastante brusca, pero existe una gran diversidad en las modalidades de esta transición debidas a procesos inflamatorios, o de reparación. etc.

\section{Glucógeno del epitelio}

De todo ginecólogo es bien conocido el llamado Test de schiller, en el que embadurnar el cuello uterino con solución iodo-iodurada de Lugol, el epitelio cervical normal que contiene glucógeno, adquiere una coloración carmelita oscuro o caoba, a cambio de que los sitios en donde este epitelio se ha transformado o desaparecido aparecen como zonas iodo-negativas. Este es un test clínico demostrativo de la carga en glucógeno del epitelio y su valor estriba en indicarle al examinador los sitios sospechosos en donde tomar las biopsias. Ya desde antes de la iniciación de este test de Shiller, Ascheim habia llamado la atención sobre el estudio histológico del glucógeno en los epitelios uterinos, pero indudablemente ha sido Moricard (4) quien ha hecho énfasis sobre la importancia de tales estudios anatomo-patológicos y quien ha sido el propulsor de la técnica de la goma iodada como medio de discriminación y de selección en el estudio de las biopsias sospechosas de carcinoma intra-epitelial. El insiste, y con razón, que hasta ahora nunca ha encontrado un corte de un epitelio en que concomitantemente con las transformaciones 
de un carcinoma intra-epitelial verdadero, existiera una carga con glucógeno normal. Esto no quiere decir que todo epitelio en el que desaparezca el glucógeno es carcinomatoso.

En las seiscientas y tantas biopsias estudiadas para la realización de este trabajo, con el fin de investigar si la carga en glucógeno estaba ausente o en vía de desaparición, según la lesión que presentaba el cervix, hemos empleado la técnica aconsejada por Moricard (5), así: fijación en Bouin alcohólico preparado con:

Solución alcohólica saturada

$\begin{array}{llllllllllllll}\text { Acido pícrico } & \ldots & \ldots & \ldots & \ldots & \ldots & \ldots & \ldots & \ldots & \ldots & 30 & \text { c. } & \text { c. } \\ \text { Formal } \ldots & \ldots & \ldots & \ldots & \ldots & \ldots & \ldots & \ldots & \ldots & \ldots & 12 & \text { c. } & \text { c. } \\ \text { Acido acético } & \ldots & \ldots & \ldots & \ldots & \ldots & \ldots & \ldots & \ldots & 3 & \text { c. } & \text { c. }\end{array}$

Habitualmente se deja en este líquido durante veinticuatro a cuarenta y ocho horas. Después se pasa a alcohol absoluto, xilol, parafina, etc. Luego se colorea con goma yodada, la cual se prepara de la manera siguiente:

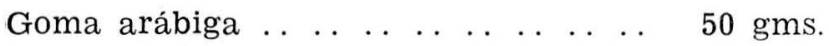

Agua destilada . . . . . . . . . . . . . . . 150 c. 15.

Esto se disuelve al calor, se filtra dos o tres veces y cuando está fría se agrega un gramo de yodo y tres gramos de yoduro de potasio disueltos en un centímetro de agua. La solución se conserva sin alteración de tres a cuatro semanas.

En el tejido normal se aprecia al microscopio que el glucógeno toma un color carmelita caoba y un color amarillo claro, el color del Bouin, donde no existe glucógeno. En el epitelio patológico puede o no existir glucógeno. En las preparaciones del cuello de la niña de cinco años mencionada antes (figuras números I, I-A y I-B), no se demostró nada de glucógeno. Esto nos hace apreciar la consabida noción de que para que se manifieste la presencia del glucógeno es necesario que haya obrado sobre el epitelio una cierta cantidad de hormona estrogénica.

Es obvio mencionar que junto con la goma yodada hemos hecho coloraciones de cortes simultáneos con hematoxilina-eosina $u$ otras coloraciones especiales.

\section{Las lesiones distróficas del cervix}

Hace un par de décadas cuando la noción del carcinoma intra-epitelial era desconocida, la definición de un carcinoma cer- 
vical era clara. Una lesión era cancerosa porque había invasión al estroma y no lo era por la ausencia de esta invasión. La deiimitación era neta. Actualmente la modificación de este criterio y la aceptación de la existencia del carcinoma intra-epitelial nos presenta una serie de problemas aún no dilucidados. Así: el criterio histológico del carcinoma intraepitelial mismo se presta todos los días a discusiones entre patólogos de reconocica talla. Por otra parte existe un gran conjunto de lesiones cervicales en que las modificaciones estructurales del epitelio recorren toda la gama de irregularidades de estratificación, atipias, hipercromatismo, etc., poniendo en guardia y dejando la duda en la mente del observador. Con estas lesiones distróficas, diagnosticadas erróneamente con frecuencia como carcinomas intra-epiteliales verdaderos a las que nos queremos referir. Aceptamos la definición de Moricard (4) de que "estas lesiones no son cancerosas, es decir, que citológicamente no se acompañan ce proliferación con anomalías mitóticas y que clínicamente no dan metástasis ni reinciden después de la extirpación local". No pretendemos en los párrafos que siguen agotar el tema y estamos concientes de que vamos a disentir con muchos conceptos, pero tratándose de lesiones aún en estudio, hemos creído de valor el somero repaso que presentamos.

Pero antes es menester que hagamos un pequeño aparte respecto a los términos distrofia y displasia. Etimológicamente distrofia significa: error o mal en la alimentación y en el crecimiento y el Diccionario de la Lengua lo define como "estado patológico que afecta a la nutrición y al crecimiento". Displasia significa error en el tejido. Así, cualquiera de los términos, dos términos, sería adecuado para distinguir el conjunto de las lesiones que nos ocupan. Sin embargo, como desde hace algún tiempo un buen número de autores en especial norteamericanos (9), han dado en llamar displasia únicamente a la lesión, que discribiremos más adelante como hiperplasia o hiperactividad basal 7 lo han hecho sinónimo de ella, hemos escogido por esto al igual que los autores europeos, en especial franceses (4), el término de distrofias para englobar todo el conjunto de lesiones.

Metaplasias.-Lesión basal frecuentemente encontrada; consiste en la diferenciación de un epitelio cilíndrico en pavimento u a la inversa. La metaplasia escamosa especialmente la de la: glándulas endocervicales ocasionalmente da lugar a confusión, pero en ella como bien lo describe Marsh (9), a pesar de que en 
los estados tempranos hay poca o ninguna tendencia a formar parte capas diferenciadas, las mitosis son normales, no hay anormalidades nucleares notorias ni células discarióticas y es posible encontrar restos del epitelio columnar que tapiza previamente las glándulas. Los patólogos alemanes acuñaron el término de "epidermización" (3) para muchas de estas metaplasias. Los pólipos endocervicales la muestran con buena frecuencia.

En cuanto al contenido en glucógeno, presentamos como ejemplo uno de los muchos casos encontrados en las enfermas del Instituto Nacional de Cancerologia, paciente de veintinueve años, que consultó por flujo vaginal blanco-amarillento, el reporte histopatológico (número 11.636), fue de metaplasia (figuras números II y II-A), el glucógeno existía en algunos sitios y $\in n$ otras había desaparición. El tratamiento consistió en una electrocoagulación.

Novak (24) y muchos otros, han insistido sobre la banalidad de este tipo de lesión que no puede ser considerada como lesión precancerosa, aunque a veces la proliferación es acentueda.

Según Fluhmann (22), es necesario distinguir dos tipos de metaplasia escamosa: una regenerativa ocasionada por traumatismos o inflamaciones y que constituye un proceso de reparación epitelial y otra originada como resultado directo de un estímulo hormonal estrogénico intenso y cuya existencia ha sido comprobada experimentalmente tanto en humanos como en roedores. Esta última ha sido llamada prosoplasia (Nesbitt) (17), cuando se encuentra un epitelio altamente diferenciado.

Leucoplasias.—Lesiones clínicamente diferenciables a simple vista o con el colposcopio, se muestra como lo indica su nombre en la forma de placas blanquecinas. Placas gruesas cornificadas, hiperkeratinizadas, que recubren un epitelio activo inmaduro, como dice Moricard (4) con la formación de un estrato granuloso en las capas superficiales, con gránulos oscuros que han sido interpretados como de eleidina o de querato-hialina y puentes intercelulares notorios. Se asocia usualmente a un cierto grado de hiperplasia basal anormal. Por esto él termino de leukoplasia encierra muy distintos grados de anormalidad y los conceptos respecto a ella difieren enormemente. Si recordamos los trabajos originales de Hinselmann, para él toda leukoplasia representaba un estado precanceroso, a cambio de que Meyer, Novak (23), y muchos otros la consideran como una lesión banal ya que son pocos los casos desarrollados sobre la base de una leukoplasia e 
insisten en que hay "tanta justificación para considerar la leucoplasia como una lesión precarcinomatosa, como que por el hallazgo ocasional de carcinomas en pólipos se pueda afirmar que los pólipos son precursores de cáncer". Sin embargo, es que, como hemos dicho, se han abarcado bajo esta denominación desde simples hiperqueratosis hasta lesiones casi infiltrativas.

Anotamos que en el término paraqueratosis (1) hace relación a la queratinización imperfecta con retención del núcleo, €n las capas superficiales del epitelio. La capa granulosa se encuentra ausente en las áreas de paraqueratosis. $\mathrm{Y}$ así se llama también paraleucoqueratosis o leucoparaqueratosis a aquellas lesiones iodo-negativas con paraqueratosis de los estratos superficiales y a la leukoplakia verdadera, Hertig (25) la designa con el nombre de leukokeratosis o leukohiperqueratosis.

En casos de prolapso (en donde la leucoplasia es basal), se presentan digitaciones que penetran profundamente en el tejido conjuntivo por hiperacantosis; pero en ausencia de prolapso si se encuentra una lesión leukoplásica en franca proliferación e hiperqueratosis y sobre todo si hay una hiperplasia basal notoria, esta lesión debe ser vigilada cuidadosamente, extirpada y su cicatrización observada. Uno de nuestros casos presentaba la asociación de por sí interesante de carcinoma in-situ y leukoplasia.

Mencionemos también otro caso: mujer que consultó por hemorragias genitales de varios años de duración y en que la biopsia mostró leukoplasia (figuras números III y III-A) (protocolo número 11.021), con gran cantidad de globos córneos y abuncante glucógeno, lo que es al parecer bastante raro, ya que Moricard, tantas veces citado, afirma que generalmente hay desaparición completa del glucógeno. En el caso de la asociación con el carcinoma in-situ observamos dentro de la leukoplasia zonas con glucógeno y zonas desprovistas de él, pero no pudimos observar la amputación neta del glucógeno.

Hiperplasia.-En su forma más simple, la hiperplasia es el espesamiento del epitelio, por aumento en el número de sus células, que se puede considerar como un proceso reaccional epitelial motivado por un proceso inflamatorio, el cual produce una proliferación maligna muchas veces con un proceso de reparación. Sin embargo, es éste el grupo más complejo, pues dentro de ellas es necesario considerar aquella serie de lesiones que algunos engloban bajo el término de displasias y que se conoce 
más comúnmente, sobre todo en la literatura norteamericana, con el nombre de hiperactividad celular basal (prickle cell hyperplasia) o hiperplasia basilar o mejor hiperplasia basal. En ellas puede haber o no aumento del espesor del epitelio. Puede haber o ro presencia de glucógeno, de ahí que Moricard (4) las divida en hiperplasias con carga de glucógeno abundante e hiperplasias con carga glucógeno regular o poca. Lo que llama la atención es que, como su nombre lo indica, la actividad de la capa basal en palizada aumenta y en vez de existir una capa basal neta de células perpendiculares al estroma, ellas reemplazan en todo o en parte al resto de capas del epitelio, resultando así una pérdida de la estratificación normal del epitelio con hipercromatismo y muchas veces con irregularidad o fusión de núcleos y aumento de mitosis.

Estas lesiones son las que han dado lugar a buen número de confusiones y de controversias, pues realmente muchas de ellas están en el límite de las neoplasias, ya que existe toda una gama de variaciones entre el extremo de la línea que todo patólogo consideraría como lesión benigna, constituído por una hiperplas.ia basal parcial con núcleos y mitosis normales y poco polimorfismo y en el otro extremo de que la hiperplasia basal ha cogido todo el espesor del epitelio con pérdida de la estratificación, hipercromatismo, polimorfismo, y aumento de las mitosis. Solo nos falta agregar en estas últimas, discariosis y atipias, para tener el cuadro de un carcinoma intra-epitelial. Se comprende, pues, que el diagnóstico diferencial sea en repetidas ocasiones extremadamente complejo. Aquí es donde nos presenta mayor ayuda como método de discriminación la goma iodada para descubrir el contenido en glucógeno.

En las biopsias estudiadas para este trabajo encontramos varios casos de hiperplasia. Presentamos algunos de ellos: uno el de una mujer de cuarenta años, que consultó por flujo vaginal amarillento, con diagnóstico clínico de tricomoniasis, la biopsia mostró hiperplasia y queratosis exocervical (protocolo número 11.605) (figuras números IV y IV-A). El glucógeno estaba disminuído.

Otro caso es el de una paciente que venía presentando hemorragias genitales ligeras por espacio de cuatro años. La biopsia mostró hiperplasia con ausencia del glucógeno. La lesión fue electrocoagulada simplemente y la enferma evolucionó hacia la curación (protocolo número 11.370) (figuras números $\mathrm{V}$ y V-A). 
Un caso de cervicitis pseudo erosiva asociado a hiperplasia fue el de una enferma de veintiocho años que consultó por flujo hemático. El estudio de la biopsia dio como resultado hiperplasia y cervicitis. El glucógeno ausente en algunas zonas estaba en otras abundante (protocolo número 11.265) (figuras números VI y VI-A).

Galvin Jones y Telinde (18), sobre 197 casos de hiperactiviclad basal, clasificados en tres grados, de acuerdo con la intensidad de esta hiperactividad, encontraron que en 33 o sea el $17 \%$. existía un carcinoma no invasor. La importancia de la clasificación del grado de hiperplasia basal resalta por el hallazgo de que solo un $2 \%$ de aquellos casos catalogados como grado o estado I de hiperactividad basal eventualmente probaron ser carcinomas intra-epiteliales, a cambio de que un $65 \%$ de aquellas en estado III, el más avanzado de hiperactividad basal, finalmente mostraron un carcinoma in-situ.

Hiperplasia glandular.-Dentro de los protocolos anátomopatológicos de las biopsias cervicales estudiadas en el Instituto iio es raro encontrar este término. El patólogo se refiere con él a aquellos casos o cortes en los cuales existe un aumento marcacio de glándulas cervicales, sin que necesariamente haya aumento del espesor del epitelio glandular. Esto es frecuente en las cervicitis polipoides. En el caso que presentamos también existía hiperplasia epitelial concomitante (figuras números VII y VII-A).

Anaplasia regenerativa.-Es posible encontrar en el epitelio en vía de regeneración de un cuello erosionado pequeñas placas de núcleos hipercromáticos y atípicos, con poca estratificación y rodeados de cambios inflamatorios. Es a esta lesión que puede dar lugar a sospechas de difícil interpretación cuando el corte histológico recae precisamente sobre ella, a lo que Hertigh (25). ha llamado anaplasia regenerativa o de reparación epitelial.

Por otra parte el término de anaplasia es frecuentemente usado para describir grupos de células inmaduras o mal diferen-ciadas con núcleos hiperactivos e irregulares.

Hipoplasias.-Esta lesión en la que el espesor del epitelio está disminuído se origina por trastornos endocrinos (castración, hipoestrogenismo, etc.) o de receptividad misma del epitelio (metrosis de receptividad de Moricard) (5). La mencionamos únicamente porque en ella se pueden encontrar núcleos desiguales, pero es obvio que no hay ningún signo de proliferación o creci- 
miento que la acerque a las lesiones que hemos comentado previamente.

Ultimamente en el Departamento de Ginecología del Instituto Nacional de Cancerología, revisamos al azar 757 protocolos ristopatológicos de enfermas con lesiones cervicales no neoplásicas encontrando la siguiente incidencia:

\begin{tabular}{|c|c|c|}
\hline Hiperplasias . & $\begin{array}{llllllllll}\ldots & \ldots & \ldots & \ldots & \ldots & \ldots & \ldots & \ldots & \ldots\end{array}$. & 159 \\
\hline Metaplasias . & $\begin{array}{lllllllllll} & \ldots & \ldots & \ldots & \ldots & \ldots & \ldots & \ldots & \ldots & \ldots\end{array}$ & 39 \\
\hline Leucoplasias & $\begin{array}{lllllllll}\ldots & \ldots & \ldots & \ldots & \ldots & \ldots & \ldots & \ldots & \ldots\end{array}$ & 2 \\
\hline Acantosis .. & $\begin{array}{lllllllll} & \ldots & \ldots & \ldots & \ldots & \ldots & \ldots & \ldots & \ldots\end{array}$ & 4 \\
\hline Cornificación & isimple $\ldots \ldots \ldots \ldots \ldots$ & 1 \\
\hline
\end{tabular}

El resto fue diagnosticado como cervicitis crónica.

Esta incidencia que corresponde a un $27,1 \%$ de lesiones distróficas cervicales parece un poco alta a primera vista, pero en realidad no lo es si recordamos que era un conjuto de muestras no representativo de la población femenina en general, sino de un grupo total de enfermas con lesiones cervicales tan suficientemente claras que obligaron a la toma de biopsias.

\section{MODIFICACIONES DEL EPITELIO CERVICAL EN EL EMBARAZO}

Ya desde 1927 Stieve y luego Hofbauer en 1923 (citados por Nesbitt) (17), demostraron que durante el embarazo ocurren modificaciones notorias tanto del epitelio glandular como del epitelio pavimentoso del cervix. La importancia de tales modificaciones ha sido revivida durante los últimos años por el hallazgo de verdaderos carcinomas intra-epiteliales concomitantes con la preñez y por el hecho de que varios de estos casos diagnosticados como carcinoma in-situ regresaron o parecieron regresar en el puerperio.

Los cambios endocervicales son bien conocidos y establecidos. El epitelio glandular prolifera intensamente y los espacios glandulares se distienden y llenan de moco para llegar a formar El llamado tapón mucoso, haciendo entonces protrusión hacia afuera del canal endocervical. Como lo anota Eastman (21) exis1e, al igual que, siempre que hay eversión del epitelio glandular, una tendencia del epitelio escamoso a recubrir rápidamente este 
epitelio glandular expuesto, por procesos de epidermización y metaplasia. Estos procesos de epidermización se rodean frecuentemente de infiltración notoria por células inflamatorias.

En el exocervix, el epitelio pavimentoso sufre también modificaciones, a más de las anotadas de epidermización, atribuídas por la mayoría de los autores al aumento progresivo y sostenido ce los niveles hormonales en especial del nivel estrogénico. Murphy y Herbut (13), en un estudio de 50 biopsias tomadas en embarazadas, dividieron estas alteraciones en dos grupos; 1) Aumento de espesor del epitelio escamoso, hecho sobre todo a expensas de las capas superficiales. Esta hiperplasia fisiológica es constante en todos los especímenes; 2) Aumento de la actividad cie la capa basal en un $6 \%$ de los casos. Para Nesbitt (17), sin embargo, esta hiperplasia basal ocurre en $20 \%$ de los casos, pero la hiperactividad basal en la mitad de los casos estaba localizada únicamente en el epitelio endocervical. Eastman (21) hace notar que Rosenthal mostró que los mismos cambios suceden en el cervix fetal. Según Nesbitt (17), parece que hay un aumento en la incidencia de hiperactividad basal en los embarazos subsiguientes de acuerdo con el grado de hiperactividad en el embarazo inicial.

Nesbitt y Hellman (26), sobre 300 embarazadas encontraron los siguientes cambios: "hiperactividad basal del ectocervix en $6,8 \%$ de los casos y epidermización superficial en 28,7\%. Hiperplasia glandular epitelial en $47,4 \%$. Hiperplasia adenomatosa en $44,1 \%$. Epidermización en $62,7 \%$. Y carcinoma intra-epitelial en $0,66 \% "$.

Hellman (16) ha llamado células de reserva (reserve cells), a las células basales del endocervix y ha hecho notar que estas células por sus potencialidades múltiples pueden llegar a mostrar cambios atipicos de hiperplasia muy similares si no idénticos al carcinoma intra-epitelial, cuando se les ha sometido a un estímulo estrogénico intenso ya experimentalmente, ya en el curso de una preñez o ya cuando existe un tumor de la granulosa. Son éstas lesiones las que son más susceptibles de regresar. En cambio las hiperplasias basales del ectocervix que han cogido el espesor del epitelio (hiperplasias basales grado III de Nesbitt), persisten en buen número de casos después de que el embarazo ha pasado. Así Greene (14) y Peckham (15), insisten en que es. tas lesiones no son cambios específicos inherentes al embarazo, sino hallazgos incidentales de verdaderas hiperactividades epiteliales fustigadas, talvez por el embarazo, pero no ocasionadas 
por él. Sobre 14 casos de Greene (14), en los que se había hecho $\epsilon !$ diagnóstico de carcinoma intra-epitelial, durante el embarazo, la lesión persistió en 12, después de la terminación de la preñez. Así mismo en los 19 casos de Peckham (15), que él divide en hiperplasias basales atípicas y lesiones sospechosas (es decir, lesiones que no merecen aún por sus característices la categoría de carcinomas intra-epiteliales, pero en los que la anomalía era aún más intensa que una hiperplasia basal atípica), la mayoría de las lesiones persistieron y uno de ellos progresó a un carcinoma intra-epitelial en un periodo de tres años, a través de dos embarazos. El reverso de la medalla, son los casos de Epperson (12) Nesbitt y Hellman (26), en los que alteraciones que en la no embarazada se hubiera catalogado como carcinoma intra-epitelial, regresaron después del embarazo en controles hasta de veintidós meses después del parto.

Como se deduce de los anteriores párrafos el acuerdo entre los investigadores no está hecho y si en la no embarazadia para hacer el diagnóstico de un verdadero carcinoma intra-epitelial necesitamos, repetidas biopsias, amputación del cuello, etc., en la embarazada tenemos que recurrir no solo a los controles periódicos de biopsias, citología, etc., durante el embarazo, si no hasta verificar la persistencia de la lesión en el puerperio tardío antes de tratar la enferma definitivamente.

De nuestra propia observación poco o nada podemos decir respecto a estas lesiones durante el embarazo, por varios motivos, el principal de los cuales es que el material que usamos para este trabajo no provino de un centro de maternidad sino en contadísimos casos. Solo presentamos la microfotografía de una biop-sia de cuello en una embarazada en la cual existía una hiperplasia moderada (figuras números VIII y VIII-A).

\section{CARCINOMA INTRAEPITELIAL. INVESTIGACION DEL GLUCOGENO}

A pesar de que por definición simple el término carcinoma intra-epitelial o in-situ se refiere al "cuadro histológico presentado por el epitelio cervical en que las células individuales a través de todo el espesor de las capas epiteliales presentan las nismas características de las del carcinoma invasor"; como henos dicho antes el criterio histológico del carcinoma intra-epitelial no ha llegado a una interpretación exacta. Así lo demuestran las encuestas experimentales hechas en Europa y Estados 
Unidos, en las que sobre una serie de cortes histológicos de carcinomas intra-epiteliales, enviados a diferentes patólogos de reconocida talla, solo estuvieron de acuerdo en el diagnóstico fina] cn un porcentaje tan reducido como 5 o $10 \%$.

Por esto queremos transcribir, casi a la letra, dos conceptos. El primero son las conclusiones de los Laboratorios de la Clínica Ginecológica de París (4). Dice: "El diagnóstico histológico no puede estar fundado sino sobre grupos de criterios, de los cuales ios más importantes son:

\section{Anomalias celulares}

a) Anaplasia: Irregularidad de talla y forma de las células basofilia del citoplasma, disminución o desaparición del glucógeno, aumento de la relación núcleo-citoplástica.

b) Atipias nucleares: Gigantismo, multiplicidad de los núcleos polilobulados, anomalías nucleares, tales como aumento de volumen o de número.

c) Anomalias de la proliferacin: cuantitativa: Mitosis en número excesivo. Cualitativa: mitosis anormales, anomalías de posición de los cromosomas, posibilidad de polipoidias. Topográficas: presencia de mitosis en las capas superficiales.

\section{Anomalias arquitecturales}

a) Discontinuidad entre el revestimiento normal y el revestimiento pablógico por razón de las anomalías descritas.

b) Trastornos estructurales con desproporción del espescr ielativo de las diferentes capas.

Cuando todas estas características coexisten el diagnóstico de carcinoma intra-epitelial es probable pero ninguna de ellas individualmente es específica".

El segundo concepto_criterio es el de Memoir Marsh (9), quien divide los carcinomas intra-epiteliales en: "1) Tipo anaplástico que recuerda los estados del carcinoma avanzados invasor franco; 2) Tipo inmaduro o poco diferenciado caracterizado por: ausencia de puentes intercelulares, bordes celulares esfumados, núcleos apelotonados como resultado en el cambio de la reación núcleo-citoplásmica, núcleos hiper o hipocromáticos, mitosis anormales, estratificación perdida aunque puede haber esbozo de ella, y 3) Tipo maduro o bien diferenciado que posee las mismas características de la anterior, excepto porque es una 
lesión cornificante con capa de queratina inmediatamente por encima de la capa granular".

En los casos de carcinoma intra-epitelial, estado 0 de este ६rupo de biopsias, en los que investigamos la carga en glucógeno inallamos ausencia de glucógeno, datos sobre el cual ya hemos insistido y acerca del que Moricard (6), ha recalcado la importancia. Sin embargo, a diferencia de este autor francés, no encontramos en la mayoría de los casos la amputación brusca, neta ciel glucógeno tan nítida y característicamente como él lo describe. Esto no quita valor al papel discriminativo de la goma, iodada, pues basta con que no haya glucógeno, desaparezca él gradual o bruscamente (figuras números IX y IX-A) (protocolo número 11.416).

\section{IRESUMEN Y COMENTARIOS DE LOS CASOS DE CARCINOMA IN-SITU, PRESENTADOS}

Se presentan 21 casos de carcinoma intra-epitelial o in-situ cie los cuales los 14 primeros han sido estudiados, diagnosticados y tratados en el Instituto Nacional de Cancerología, en éstos están incluídos los presentados en dos trabajos anteriores (19531955). Los 7 restantes reúnen 5 casos del Hospital de San Juan de Dios de Bogotá y dos facilitados por el doctor López-Escobar (casos números 16, 17, 18, 19, 21 y 15, 20).

Los 21 casos fueron aceptados previo estudio y revisión de todas las placas histológicas en asocio con los doctores Alfonso Méndez, Egon Lichtenberger y Armando Santamaría y se rechazaron aquellos que no reunian condiciones para aceptarlos con criterio de certeza. De ahí que en este trabajo no se presenten 3 casos referidos anteriormente, por considerarlos dudosos.

La edad de las pacientes estudiadas tuvo como cifras límites entre los veintitrés y sesenta y un años. En la tercera décade de la vida, 6 casos; en la cuarta, 3 casos; en la quinta, 10 casos; en la sexta, 1, y en la séptima, 1; es decir, que los 19 casos se presentaron en enfermas menores de cincuenta años. Ocho de las enfermas tuvieron uno o dos partos, las 13 restantes eran grandes multíparas.

Los diagnósticos clínicos de impresión fueron en 9 casos de cervicitis crónica, en 5 casos se sospechó lesión maligna (en uno de ellos por colposcopia), los otros diagnósticos fueron de hiperplasia endometrial en 3 casos, de prolapso genital en 2 , endome- 
tritis en 1 y fibromatosis en 1. Tres de los casos del Hospital de San Juan de Dios fueron diagnosticados al examen rutinario de la pieza quirúrgica sin previa biopsia del cervix (2 prolapsos corre gidos por técnica de Manchester-Fothergill y una fibromatosis tratada con histerectomía total).

En 8 de los casos hay datos de citología vaginal; en 6 de ellos fue positiva para células tumorales.

En 5 casos se practicó con fin diagnóstico (para destacar invasión), amputación del cervix. En 4 de ellos se confirmó el diagnóstico de carcinoma in situ, en uno no se encontraron nuevos focos posiblemente debido a que fueron extirpados en las primeras biopsias. Además en 2 casos se hizo raspado fraccionado de endometrio y endocervix, confirmando el diagnóstico previo.

Vale la pena llamar la atención sobre los casos números 1 y 3. El primero con biopsia de carcinoma in-situ en 1942 y carcinoma invasivo con biopsia en 1954; el segundo con biopsia de carcinoma in-situ en 1944 y carcinoma invasivo en 1950.

En el Instituto Nacional de Cancerología se rechazaron 4 historias que corresponden a los números 9.213, 32.005 y 43.219 ciagnosticadas como casos de carcinoma in-situ, pero que al revisar las láminas los patólogos no estuvieron de acuerdo, clasificándolas como displasias atípicas cervicales.

Además se encontraron cuatro casos que conviene comentar al margen de este trabajo y que no fueron incluídos por ser invasivos, teniendo algunas biopsias con diagnóstico de carcinoma in-situ y discrepancias en los diagnósticos clínicos. Resumimos brevemente estas historias:

Historia clínica número 33.998 .

Paciente: P. V. de R.

Consulta en junio de 1954.

Edad: cincuenta y cinco años. Menopáusica.

Diagnóstico: pólixo endocervical.

Se tomó biopsia de él. Resultado anátomo-patológico: pótipo con degeneración maligna.

En julio de 1954 se practicó histerolinfaenectomía.

Resultado anátomo-patológico: fibroma polipoide endocervical con focos de carcinoma in-situ. Carcinoma intra-epitelial en exocervix. Gánglios negativos. 
Comentario.-En este caso el carcinoma invasivo posiblemente estaba localizado solamente en el pólipo que se extirpó en la biopsia y coincidía con focos de carcinoma intra-epitelial en un fibroma polipoide endocervical y en el epitelio exo-cervical.

Historia clínica número 34.270 .

Paciente: C. P. de G.

Consulta en junio de 1954.

Edad: treinta y cuatro años.

Remitida de Barranquilla con una biopsia firmada por el doctor J. L. Goforth, con resultado de carcinoma escamo-celular invasivo grado III. Se tomaron nuevas biopsias múltiples en el Instituto con resultado de cervicitis crónica.

En agosto de 1954 se practicó amputación del cervix para cortes seriados. El resultado histo-patológico fue de focos de carcinoma in-situ que se insinúan en el epitelio de algunas glándulas. En vista de la primera biopsia, se practicó histolinfadenectomía, en agosto de 1954.

La pieza quirúrgica fue negativa para tumor.

Comentario.-Como no se conoció la placa de la primera biopsia fue necesario considerar el caso invasivo a pesar de los cortes seriados de cervix.

Historia clínica número 42.410.

Paciente: A. M. D. R.

Consulta en abril de 1957.

Edad: sesenta años. Menopáusica.

Remitida del Hospital de San Juan de Dios con el diagnóstico de carcinoma invasivo del cervix.

Biopsias positivas.

Se observó una leucoplasia difusa y se tomaron nuevas biopsias y citología. La citología fue negativa, y así mismo las biopsias. Se repitieron en mayo de 1957. El resultado fue de carcinoza in-situ, pero clínicamente persistía la sospecha de carcinoma invasivo en el endocervix. Se propuso la amputación para aclarar diagnóstico, intervención que no se realizó y le fue practicada histerectomía total. En la pieza quirúrgica se encontró carcinoma invasor y en vista de ésto se complementó con el tratamiento roentgenterápico pendular.

Comentario.-No había diagnóstico seguro al practicar la jntervención por falta de revisión de las láminas del Hospital 
remitente y posteriormente por haber prescindido de la amputación del cervix para estudio histológico.

Historia clínica número 42.967.

Paciente: E. A. v. de M.

Consulta en junio de 1957.

Edad: cincuenta y ocho años. Menopáusica.

Consulta por flujo sanguinolento de veinte días de evolución.

Diagnóstico clínico: pólipos del cervix. ¿Degeneración?

Se tomaron biopsias.

Diagnóstico histológico: carcinoma in-sîtu.

En vista del resultado se resolvió tomar múltiples biopsias cuyo resultado fue de nuevo, carcinoma in-situ.

Se practicó entonces amputación del cervix para cortes seriados. Estos demostraron carcinoma invasivo.

Se practicó histerolinfadenectomía y el resultado del espécimen fue: carcinoma invasivo. Gánglios negativos.

Comentario.-El estudio de este caso fue bien conducido y demuestra la utilidad y conveniencia de la amputación del cervix para estudio histológico en cortes seriados. 


\begin{tabular}{|c|c|c|c|c|c|c|c|}
\hline $\begin{array}{c}\text { Fecha } \\
\text { Caso } \\
\text { Historia }\end{array}$ & $\begin{array}{c}\text { Edad } \\
\text { Paridad }\end{array}$ & $\begin{array}{l}\text { Diagnóstico } \\
\text { Clínico }\end{array}$ & Biopsia & Citología & Tratamiento & $\begin{array}{c}\text { Pieza } \\
\text { Quirúrgica }\end{array}$ & OBSERVACIONES \\
\hline $\begin{array}{l}\text { Julio-40 } \\
1 \\
5.799 \\
\text { T. M. de F. }\end{array}$ & $\begin{array}{r}45 \\
8\end{array}$ & Cervicitis & $\begin{array}{l}\text { Julio- } 40 \\
\text { Cervicitis } \\
\text { Agosto- } 54 \\
\text { Ca. In-Situ } \\
\text { Agosto-54 } \\
\text { Ca. invasivo }\end{array}$ & No tiene & $\begin{array}{l}\text { Radium y } \\
\text { RX. } 1940\end{array}$ & No & $\begin{array}{l}\text { Mastectomía radical 1940 para Ca. } \\
\text { del seno y RX. posteriores. Radium } \\
\text { y RX. para Ca. invasivo de cervix } \\
\text { en 1954. } \\
\text { En B/s. cervix } 1942 \text { diagnóstico de } \\
\text { Ca. In-Situ. La enferma no regresa } \\
\text { sino doce años después con un car- } \\
\text { cinoma invasivo. }\end{array}$ \\
\hline $\begin{array}{c}\text { Nov. }-50 \\
2 \\
10.587\end{array}$ & $\begin{array}{r}29 \\
4\end{array}$ & $\begin{array}{l}\text { Cervicitis } \\
\text { Crónica }\end{array}$ & $\begin{array}{l}\text { Nov. }-50 \\
\text { Ca. In-Situ }\end{array}$ & $\begin{array}{l}\text { Dic.-52 } \\
\text { Negativa }\end{array}$ & $\begin{array}{l}\text { Amputación } \\
\text { de Cervix. } \\
\text { Dic.-50 }\end{array}$ & Ca. In-Situ & $\begin{array}{l}\text { Controlada con citología. } \\
\text { Actualmente bien. }\end{array}$ \\
\hline C. P. de C. & & & $\begin{array}{l}\text { Dic. }-50 . \\
\text { Ca. In-Situ }\end{array}$ & $\begin{array}{l}\text { Mar.-53 } \\
\text { Negativa }\end{array}$ & & & \\
\hline $\begin{array}{l}\text { Oct. }-44 \\
3 \\
11.089 \\
\text { C. F. de C. }\end{array}$ & 44 & Endometritis & $\begin{array}{l}\text { Oct. }-44 \\
\text { Ca. In-Situ } \\
\text { Sep. }-49 \\
\text { Cervicitis } \\
\text { Ago.-50 } \\
\text { Ca. invasivo }\end{array}$ & $\begin{array}{l}\text { Ago.-50 } \\
\text { Células } \\
\text { Tumorales }\end{array}$ & $\begin{array}{l}\text { Oct. }-50 \\
\text { Laparatomía. } \\
\text { Anexectomía } \\
\text { Oct.-50 } \\
\text { Radium y } \mathbf{R x} \text {. }\end{array}$ & $\begin{array}{l}\text { En anexos: } \\
\text { Anexitis } \\
\text { bilateral }\end{array}$ & $\begin{array}{l}\text { Diagnóstico de Ca. In-Situ: } 1944 \\
\text { B/s. de 1949: cervicitis. } \\
\text { En ago.-50 Diagnóstico clínico: Ca. } \\
\text { del cervix ETD. } 1 \text { con B/s. de Ca. } \\
\text { invasivo. Laparatomía exploradora: } \\
\text { Anexectomía. } \\
\text { No se hizo histerectomia por estado } \\
\text { inflamatorio. Se hizo tratamiento } \\
\text { con Radium y RX. }\end{array}$ \\
\hline $\begin{array}{l}\text { Oct. }-50 \\
4 \\
24.616 \\
\text { C. J. de H. } \\
\end{array}$ & 48 & Ca. Cervix? & $\begin{array}{l}\text { Oct.-50 } \\
\text { Ca. In-Situ } \\
\text { Nov.-50 } \\
\text { Ca. In-Situ }\end{array}$ & $\begin{array}{l}\text { Oct.-50 } \\
\text { Células } \\
\text { Tumorales }\end{array}$ & $\begin{array}{l}\text { Radium y RX. } \\
\text { N } 8-50\end{array}$ & No & $\begin{array}{l}\text { Control de tres años: enferma en } \\
\text { buenas condiciones generales. } \\
\text { Restos del cervix: sano. }\end{array}$ \\
\hline $\begin{array}{l}\text { Nov. }-50 \\
5 \\
24.869 \\
\text { C. A. A. }\end{array}$ & $\begin{array}{r}30 \\
1\end{array}$ & $\begin{array}{l}\text { Cervicitis } \\
\text { Crónica }\end{array}$ & $\begin{array}{l}\text { Oct.-50 } \\
\text { Metaplasia } \\
\text { Nov. }-50 \\
\text { Ca. In-Situ }\end{array}$ & No tiene & $\begin{array}{l}\text { Histerolin- } \\
\text { fadenectomia. } \\
\text { No-50 }\end{array}$ & Ca. In-Situ & $\begin{array}{l}\text { Las B/s. tomadas fueron del Insti- } \\
\text { tuto Nacional de Cancerologia. En } \\
\text { la pieza quirúrgica, cortes seriados } \\
\text { de cervix demostraron focos de Ca. } \\
\text { In-Situ. Gánglios: negativos. }\end{array}$ \\
\hline
\end{tabular}




\begin{tabular}{|c|c|c|c|c|c|c|c|}
\hline $\begin{array}{c}\text { Fecha } \\
\text { Caso } \\
\text { Historia }\end{array}$ & $\begin{array}{c}\text { Edad } \\
\text { Paridad }\end{array}$ & $\begin{array}{l}\text { Diagnóstico } \\
\text { Clínico }\end{array}$ & Biopsia & Citología & Tratamiento & $\begin{array}{c}\text { Pieza } \\
\text { Quirúrgica }\end{array}$ & OBSERVACIONES \\
\hline $\begin{array}{c}\text { Ene.-52 } \\
6 \\
27.716 \\
\text { A. S. de A. } \\
\end{array}$ & $\begin{array}{l}42 \\
12\end{array}$ & $\begin{array}{l}\text { Hiperplasia } \\
\text { Endometrial }\end{array}$ & $\begin{array}{l}\text { Ene.-5i2 } \\
\text { Ca. In-Situ }\end{array}$ & $\begin{array}{l}\text { Abr.-52 } \\
\text { Negativa } \\
\text { Abr.-52 } \\
\text { Células } \\
\text { Tumorales }\end{array}$ & $\begin{array}{l}\text { Histerectomia } \\
\text { total. } \\
\text { Anexec. bil. } \\
\text { Abr. }-52\end{array}$ & $\begin{array}{l}\text { Metaplasia } \\
\text { epidermoide }\end{array}$ & $\begin{array}{l}\text { No se hicieron cortes seriados del } \\
\text { cervix en la pieza quirúrgica. }\end{array}$ \\
\hline $\begin{array}{c}\text { Mar.-52 } \\
7 \\
28.132\end{array}$ & 41 & $\begin{array}{l}\text { Hiperplasia } \\
\text { Endometrial }\end{array}$ & $\begin{array}{l}\text { Mar. }-52 \\
\text { Ca. In-Situ } \\
\text { Nov. }-52 \\
\text { Ca. In-Situ }\end{array}$ & $\begin{array}{l}\text { Abr.-52 } \\
\text { Células } \\
\text { Tumorales } \\
\text { May.-52 } \\
\text { Células } \\
\text { Tumorales }\end{array}$ & $\begin{array}{l}\text { Amputación } \\
\text { Cervix } \\
\text { Histerectomía. } \\
\text { Anexec. } \\
\text { Bilateral. }\end{array}$ & $\begin{array}{l}\text { Ca. In-Situ } \\
\text { Ca. In-Situ } \\
\text { Nov. }-52\end{array}$ & $\begin{array}{l}\text { Ocho meses después de amputación } \\
\text { del cervix, nuevas B/s. de endocer- } \\
\text { vix demuestran Ca. In-Situ, por lo } \\
\text { cual se practica histerectomia. }\end{array}$ \\
\hline $\begin{array}{c}\text { Abr. }-53 \\
8 \\
30.843 \\
\text { E. O. v. V. }\end{array}$ & $\begin{array}{r}35 \\
6\end{array}$ & Cervicitis & $\begin{array}{l}\text { Abr.-53 } \\
\text { Ca. In-Situ }\end{array}$ & No tiene & $\begin{array}{l}\text { Histerectomia } \\
\text { total. } \\
\text { Anexec. bil. }\end{array}$ & Ca. In-Situ & Cortes seriados de cervix. \\
\hline $\begin{array}{l}\text { Jun.-53 } \\
9 \\
31.115 \\
\text { B. R. de G. }\end{array}$ & 43 & Cervicitis & $\begin{array}{l}\text { Jun.-53 } \\
\text { Ca. In-Situ } \\
\text { Ago.-53 } \\
\text { Ca. In-Situ } \\
\text { Ago.-53 } \\
\text { Cervicitis }\end{array}$ & $\begin{array}{l}\text { Ago.-53 } \\
\text { Células } \\
\text { Tumorales }\end{array}$ & Sin tratamiento & No & $\begin{array}{l}\text { La enferma se negó a someterse al } \\
\text { tratamiento. }\end{array}$ \\
\hline $\begin{array}{l}\text { May. }-57 \\
21 \\
\text { A. V. C. }\end{array}$ & $\begin{array}{r}30 \\
2\end{array}$ & $\begin{array}{l}\text { Cervicitis } \\
\text { Crónica }\end{array}$ & Carcinoma? & No tiene & $\begin{array}{l}\text { Histerolin- } \\
\text { fadenectomía. } \\
\text { Jun. } 57\end{array}$ & Ca. In-Situ & $\begin{array}{l}\text { La sospecha de invasión reportada } \\
\text { por el patólogo inclinó al cirujano a } \\
\text { practicar cirugía radical. La revi- } \\
\text { sión post-operatoria de la B/ con- } \\
\text { firmó que no habia invasión. La } \\
\text { enferma murió por accidente quirúr- } \\
\text { gico complicado. }\end{array}$ \\
\hline $\begin{array}{l}\text { Sep.-56 } \\
12 \\
40.681 \\
\text { M. C. de O. }\end{array}$ & 47 & $\begin{array}{l}\text { Cervicitis } \\
\text { Crónica } \\
\text { Fibromatosis }\end{array}$ & $\begin{array}{l}\text { Sep.-56 } \\
\text { Ca. In-Situ }\end{array}$ & No tiene & $\begin{array}{l}\text { Histerolin- } \\
\text { fadenectomía } \\
\text { Oct. }-56\end{array}$ & Leiomioma & $\begin{array}{l}\text { Se hizo cirugía radical por sospecha } \\
\text { clínica de invasión. Los cortes se- } \\
\text { riados de cervix mostraron de nue- } \\
\text { vo Ca. In-Situ. }\end{array}$ \\
\hline
\end{tabular}




\begin{tabular}{|c|c|c|c|c|c|c|c|}
\hline $\begin{array}{c}\text { Fecha } \\
\text { Caso } \\
\text { Historia }\end{array}$ & $\begin{array}{l}\text { Edad } \\
\text { Paridad }\end{array}$ & $\begin{array}{l}\text { Diagnóstico } \\
\text { Clínico }\end{array}$ & Biopsias & Citología & Tratamiento & $\begin{array}{c}\text { Pieza } \\
\text { Quirúrgica }\end{array}$ & OBSERVACIONES \\
\hline $\begin{array}{l}\text { Mar. }-57 \\
\quad 14 \\
42.244 \\
\text { E. S. de M. }\end{array}$ & $\begin{array}{r}48 \\
1\end{array}$ & $\begin{array}{l}\text { Cervicitis } \\
\text { Crónica } \\
\text { Ca. Cervix? }\end{array}$ & $\begin{array}{l}\text { Mar. }-57 \\
\text { Ca. In-Situ } \\
\text { Mar. }-57 \\
\text { Cervicitis } \\
\text { Crónica } \\
\text { Abr. }-57 \\
\text { Ca. In-Situ }\end{array}$ & $\begin{array}{l}\text { Abr.-57 } \\
\text { Células } \\
\text { Tumorales }\end{array}$ & $\begin{array}{l}\text { Raspado- } \\
\text { Fraccionado. } \\
\text { Abr.-57 } \\
\text { Histerectomía } \\
\text { Total } \\
\text { Mayo-57 }\end{array}$ & $\begin{array}{l}\text { Ca. In-Situ } \\
\text { Leiomioma } \\
\text { Cervicitis } \\
\text { Crónica }\end{array}$ & $\begin{array}{l}\text { Después de } 2 \text { B/s. positivas y un } \\
\text { raspado de endocervix positivo para } \\
\text { Ca. In-Situ, se practicó histerecto- } \\
\text { mía total. Posiblemente los focos de } \\
\text { Ca. In-Situ fueron extirpados en las } \\
\text { intervenciones anteriores. }\end{array}$ \\
\hline $\begin{array}{l}\text { Dic. }-56 \\
13 \\
41.523 \\
\text { R. L. } \\
\end{array}$ & $\begin{array}{r}45 \\
4\end{array}$ & Ca. Cervix? & $\begin{array}{l}\text { Dic. }-56 \\
\text { Ca. In-Situ } \\
\text { Dic.-56 } \\
\text { Ca. In-Situ }\end{array}$ & No tiene & $\begin{array}{l}\text { Amputación } \\
\text { Cervix } \\
\text { Raspado } \\
\text { Endometrio }\end{array}$ & $\begin{array}{l}\text { Cervicitis } \\
\text { Hiperplasia } \\
\text { Endometrio }\end{array}$ & $\begin{array}{l}\text { A pesar de que los cortes seriados } \\
\text { de cervix no mostraron Ca. In-Situ, } \\
\text { las biopsias tomadas cuyas láminas } \\
\text { fueron revisadas nuevamente por } 3 \\
\text { patólogos, confirmaron la lesión. } \\
\text { Control con citología vaginal nega- } \\
\text { tiva en Oct.-57. }\end{array}$ \\
\hline $\begin{array}{l}\text { Dic. }-55 \\
15 \\
\text { O. P. de A. }\end{array}$ & 53 & $\begin{array}{l}\text { Cervicitis } \\
\text { Crónica }\end{array}$ & $\begin{array}{l}\text { Dic.-55 } \\
\text { Epitelio } \\
\text { Atípico } \\
\text { Dic. } 55 \\
\text { Ca. In-Situ } \\
\end{array}$ & No tiene & $\begin{array}{l}\text { Amputación } \\
\text { Cervix. } \\
\text { Dic. }-55 \\
\text { Hist. total } \\
\text { Ene. }-56\end{array}$ & Negativa & $\begin{array}{l}\text { Las segundas } \mathrm{B} / \mathrm{s} \text {. practicadas sobre } \\
\text { cervix amputado, cortes seriados de- } \\
\text { mostraron Ca. In-Situ. }\end{array}$ \\
\hline $\begin{array}{l}\begin{array}{c}\text { Feb. }-54 \\
10 \\
33.016 \\
\text { E. P. de D. }\end{array} \\
\end{array}$ & $\begin{array}{r}30 \\
4\end{array}$ & Ca. Cervix? & $\begin{array}{l}\text { Feb. }-54 \\
\text { Ca. In-Situ } \\
\text { Feb. }-54 \\
\text { Ca. In-Situ }\end{array}$ & $\begin{array}{l}\text { Feb.-54 } \\
\text { Negativa }\end{array}$ & $\begin{array}{l}\text { Raspado } \\
\text { Fraccionado } \\
\text { Histerectomía } \\
\text { Total. } \\
\text { Anexectomía } \\
\text { Feb.-54 } \\
\text { Mar.-54 }\end{array}$ & $\begin{array}{l}\text { Ca. In-Situ } \\
\text { Ca. In-Situ }\end{array}$ & $\begin{array}{l}\text { Después de la primera B/. el raspa- } \\
\text { do de endocervix demuestra de nue- } \\
\text { vo Ca. In-Situ. En cortes seriados } \\
\text { de cuellos se encuentra Ca. In-Situ. }\end{array}$ \\
\hline $\begin{array}{l}\text { May. }-54 \\
11 \\
33.747 \\
\text { F. P. } \\
\end{array}$ & $\begin{array}{r}61 \\
1\end{array}$ & $\begin{array}{l}\text { Metrorragia } \\
\text { Hiperplasia }\end{array}$ & $\begin{array}{l}\text { May.-54 } \\
\text { Ca. In-Situ }\end{array}$ & No tiene & No & & $\begin{array}{l}\text { En la B/s. focos de metaplasia epi- } \\
\text { dermoide y focos múltiples de Ca. } \\
\text { In-Situ. La enferma no regresó a } \\
\text { tratamiento. }\end{array}$ \\
\hline $\begin{array}{l}\text { Nov. }-56 \\
17 \\
\text { M. L. }\end{array}$ & $\begin{array}{l}29 \\
11\end{array}$ & $\begin{array}{l}\text { Prolapso de } \\
\text { III grado }\end{array}$ & No tiene & No tiene & $\begin{array}{l}\text { Manchester } \\
\text { Fothergill } \\
\text { Nov.-56 }\end{array}$ & Ca. In-Situ & $\begin{array}{l}\text { Cortes seriados del cervix. Amputado } \\
\text { demostraron Ca. In-Situ. No ha } \\
\text { vuelto a control. }\end{array}$ \\
\hline
\end{tabular}




\begin{tabular}{|c|c|c|c|c|c|c|c|}
\hline $\begin{array}{l}\text { Fecha } \\
\text { Caso } \\
\text { Historia }\end{array}$ & $\begin{array}{c}\text { Edad } \\
\text { Paridad }\end{array}$ & $\begin{array}{l}\text { Diagnóstico } \\
\text { Clínico }\end{array}$ & Biopsias & Citología & Tratamiento & $\begin{array}{c}\text { Pieza } \\
\text { Quirúrgica }\end{array}$ & OBSERVACIONES \\
\hline $\begin{array}{l}\text { Ene. }-57 \\
18 \\
\text { M. C. }\end{array}$ & 38 & $\begin{array}{l}\text { Fibromatosis } \\
\text { Uterina }\end{array}$ & No tiene & No tiene & $\begin{array}{l}\text { Histerectomía } \\
\text { total sin } \\
\text { Anexectomia } \\
\text { Ene. }-57\end{array}$ & $\begin{array}{l}\text { Fibromatosis } \\
\text { Uterina. } \\
\text { Ca. In-Situ }\end{array}$ & $\begin{array}{l}\text { No hubo sospecha pre-operatoria de } \\
\text { lesión del cuello. El hallazgo se hizo } \\
\text { por estudio rutinario de la pieza qui-. } \\
\text { rúrgica. }\end{array}$ \\
\hline $\begin{array}{l}\text { Ene. }-57 \\
\quad 19 \\
\text { A. T. de V. } \\
\end{array}$ & $\begin{array}{l}40 \\
10\end{array}$ & $\begin{array}{l}\text { Prolapso } \\
\text { Genital }\end{array}$ & No tiene & No tiene & $\begin{array}{l}\text { Manchester } \\
\text { Fothergill } \\
\text { Feb.-5/7 }\end{array}$ & Ca. In-Situ & $\begin{array}{l}\text { No hubo sospecha previa de Ca. In- } \\
\text { Situ. Los cortes seriados del cervix } \\
\text { amputado lo demostraron. No ha } \\
\text { vuelto a control. }\end{array}$ \\
\hline $\begin{array}{l}\text { Abr. }-57 \\
\quad 20 \\
\text { C. I. S. de D } \\
\end{array}$ & $\begin{array}{r}23 \\
4\end{array}$ & $\begin{array}{l}\text { Ca.In-Situ } \\
\text { (colposcopia) }\end{array}$ & Ca. In-Situ & No tiene & $\begin{array}{l}\text { Amputación } \\
\text { Cervix } \\
\text { May. }-57\end{array}$ & Ca. In-Situ & Enferma en observación. \\
\hline $\begin{array}{l}\text { Feb. }-56 \\
16 \\
\text { B. T. }\end{array}$ & $\begin{array}{l}49 \\
16\end{array}$ & $\begin{array}{l}\text { Cervicitis } \\
\text { Crónica }\end{array}$ & Ca. In-Situ? & No tiene & $\begin{array}{l}\text { Histerectomía } \\
\text { Total }\end{array}$ & Ca. In-Situ & $\begin{array}{l}\text { Las primeras biopsias fueron sospe- } \\
\text { chosas de Ca. In-Situ, pero el pató- } \\
\text { logo las reporta como dudosas. Los } \\
\text { cortes seriados de cervix denicstra- } \\
\text { ron evidencia de la lesión. La enfer. } \\
\text { ma muere por hemorragia pos'-ope- } \\
\text { ratorio. }\end{array}$ \\
\hline
\end{tabular}




\section{COMENTARIOS Y CONCLUSIONES}

Consideramos que se debe unificar la terminología para definir la lesión pre-invasora del carcinoma del cervix, para lo cual debemos preferir el concepto histopatológico y escoger entonces el término de carcinoma intra-epitelial sobre los de carcinoma in-situ, carcinoma pre-invasivo y carcinoma incipiente, aun cuando todos illos sean usados indistintamente y alguno de ellos preferido por determinada escuela.

Aceptamos y comprobamos la dificultad para el diagnóstico del carcinoma intra-epitelial ya que, por ejemplo, en un reporte muy interesante del doctor Siegler (27), en el cual presenta 20 casos, a los cuales se tomaron cortes histológicos de las biopsias clel cervix, seleccionados únicamente por frotis sospechosos o positivos, pero sin evidencia clínica de cáncer y se enviaron para su estudio a 25 diferentes distinguidos patólogos, los resultados demostraron que los acuerdos en los diagnósticos no estuvieron dentro de un porcentaje aceptable y aún no hubo un solo corte histológico en el cual se hubiera tenido un acuerdo completo. Esas divergencias se presentaron aun entre patólogos de una misma institución.

En nuestra estadística que inicialmente fue un poco más numerosa, nos vimos obligados a rechazar algunos casos, diagnosticados anteriormente como carcinoma intra-epitelial, pero cuya revisión no llenaba francamente las condiciones indispensables para considerárseles como tales.

Nosotros, para confirmar este diagnóstico, hemos utilizado el siguiente criterio histológico, resumiendo los conceptos de diversos autores tales como Moricard (5), Reagan (28), Meigs (20), Marsh y Hellman (30) y otros.

Compromiso del espesor total del epitelio por:

1. Anomalias nucleares:

a) Núcleos de tamaño desigual.

b) Núcleos multilobulados.

c) Núcleos voluminosos y múltiples.

d) Desaparición del glucógeno en las capas superficiales del epitelio cervical.

e) Mitosis anormales.

f) Poliploidia elevada. 


\section{Anomalias protoplasmáticas:}

a) Basofilia del citoplasma.

b) Desaparición parcial o completa del glucógeno.

3. Pérdida de polaridad celular.

4. Pérdida de la relación núcleo-citoplasmática.

5. Pérdida de la estructura de las distintas capas del epitelio.

Esta dificultad que anotábamos para el diagnóstico del carcinoma intra-epitelial se hace aún más evidente durante el embarazo, en el cual se pueden apreciar modificaciones tales como: hiperplasia del epitelio, hiperplasia fisiológica de la basal, hiperplasia atípica de la basal, pérdida de la estratificación celular, aumento del tamaño del núcleo, hipercromatismo nuclear, atipias nucleares, lesiones que pueden desaparecer, regresar o persistir.

Campos J. Soihet (31) en un estudio sobre 200 embarazadas, encontró lesiones semejantes a las anotadas anteriormente, que en un 5\% no fue posible diferenciarlas del carcinoma intra-epitelial y, sin embargo, dichas lesiones desaparecieron a los tres meses después del parto. Concluye que las alteraciones en la morfología cervical durante el embarazo son el resultado del embarazo en sí.

Memoir Marsh (32), en un estudio sobre 4.000 embarazadas, encontró 20 casos de carcinoma intra-epitelial. Pudo controlar 18 después del parto, encontrando que la lesión persistía en 6 pacientes, después de seis meses, en 5 pacientes después de siete a doce meses y en 7 la lesión estaba presente de un año a treinta y un meses post-partum y concluye que el embarazo en sí no da lugar a lesiones morfológicas transitorias no diferenciables de las verdaderas del carcinoma intra-epitelial, que desaparece en el post-partum y que las lesiones del carcinoma intra-epitelial en el embarazo, presentan intrínsecamente el mismo problema que en la no gestante.

Sabemos ciertamente que algunas de esas lesiones como la hiperplasia del epitelio, la hiperplasia de la basal, sí pueden ser inherentes del embarazo, así como lo son también en estados relacionados con niveles estrogénicos altos, pero la divergencia en las lesiones indiferenciables del carcinoma intra-epitelial se deben posiblemente a que los que la consideran reversibles, las han apreciado no en la totalidad del epitelio, en donde, como anota Marsh, constituyen el mismo problema de la no embarazada. 
Por otra parte, es necesario tener en cuenta para explicar algunos de estos casos que han regresado, la multipontencialidad de lo que Hellman (16) ha llamado "células de reserva" aue se encuentran generalmente en el endocervix y que estimuladas por inflamaciones, hiperestrogenismo, etc., pueden llegar a producir un cuadro muy similar al del carcinoma intra-epitelial en esta región endocervical. Por esta razón se insiste, cuando se hace el diagnóstico de carcinoma intra-epitelial durante el embarazo, en concederle mucho mayor valor a las lesiones de ectocervix.

Debemos entonces nosotros ser más cautelosos en el diagnóstico del carcinoma intra-epitelial del embarazo y aún más en los controles que se verifican en el post-partum para poder seguir una conducta terapéutica efectiva y no perjudicial para la paciente.

Queremos intentar responder un gran interrogante que se ha establecido desde cuando se iniciaron los primeros estudios del carcinoma intra_epitelial: el carcinoma intra_epitelial evo. luciona hacia un carcinoma invasor? ¿Y éste' se encuentra pre_ cedido por el carcinoma intra-epitelial? No se pueden contestar categóricamente, puesto que hay varias series que nos demuestran tanto que pueden permanecer estacionarias como evoluciolaadas en un carcinoma invasor.

En la serie que nosotros presentamos hay dos casos de car. cinoma intra-epitelial, que se hicieron invasivos después de seis y doce años.

Galvin Gerald et al (33), presentaba una serie de 13 casos cie carcinoma in-situ no tratados. Tres permanecieron no invasivos después de dos, cuatro y seis años, respectivamente. Mientras que los 10 restantes progresaron a varios estados clínicos de carcinoma cervical entre uno y diecisiete años. En otra serie de 53 casos de Lee, Melnick y Walsh (33) de carcinoma in-situ sin tratamiento, por períodos hasta de tres años, no han aparecido cambios invasivos.

En otras series como la de Petersen en Copenhague, la de Kotmeier en Estocolmo, la de Nieberg en Augusta (Georgia) y la de Graham en Boston, que se han dejado también en observación sin tratamiento, en ninguna de ellas se podrá afirmar positivamente que el carcinoma intra-epitelial precede al carcinoma invasor, pero tampoco se puede negar el antecedente del carcinoma intra-epitelial en aquellos que se han hecho invasivos. 
Por otra parte, Marsh nos ha presentado un caso demostrancio una lesión invasora desprendiéndose de un epitelio normal.

En cuanto a la incidencia del carcinoma intra-epitelial Marsh $y$ Hellman (30) reportan una incidencia de $1.8 \%$ sobre 1.010 pacientes. El mismo Marsh (32) da la cifra $0.49 \%$ en más de 4.000 embarazadas. Haroldo Calvo (colombiano) y Theodore Winship (34) dan una incidencia de $0.57 \%$ sobre 1.238 casos y Carter, Cuyler, Kaufman, y Thomas, Cradick, Parker, Pette y Cherny (35) presentan una incidencia de $0.57 \%$ en el servicio ginecológico y de $0.58 \%$ en el obstétrico.

Meigs refiriéndose a estas dos últimas incidencias parejas en los servicios de ginecología y de maternidad, recalca la importan. cia de la investigación del Ca. intra-epitelial, más aún en presencia de gestación.

Nuestra incidencia, por cierto muy difícil también en determinar, ya que nuestra casuística se refiere a 21 casos, 14 de ellos ciel Instituto Nacional de Cancerología, durante los años de 1940 a 1957, los restantes del Hospital de San Juan de Dios de Bogotá y de pacientes privados, no nos permiten obtener un dato de valor estadístico, ya que fuentes de consulta han sido heterogéneas. asi como también los sistemas de investigación.

Sin embargo, podemos informar que dos casos se presentaron en los años 1940 a 1949 y los doce restantes de 1950 a julio de 1957, años en los cuales se atendió a un promedio anual de 2.444 pacientes en el servicio de ginecología.

En 1956 y los primeros seis meses de 1957, se diagnosticaron 3 casos sobre un total de 1.152 biopsias de cervix, lo cual nos daria una incidencia real de $0.26 \%$.

En una serie personal de uno de nosotros (G. L. E.) sobre 2.000 pacientes se diagnosticaron 4 casos de carcinoma intraepitelial $(0,25 \%)$.

\section{TRATAMIENTO}

Antes de iniciar el estudio sobre el tratamiento, creemos conveniente recalcar varios métodos de todos conocidos y de hace mucho tiempo atrás practicados, tales como la citología como primer paso en la investigación de malignidad; sea o no positiva, los casos sospechosos deben ser controlados por medio de biopsias múltiples tanto de las lesiones presentes como del endocervix. Es el mínimo de estudio que consideramos se debe requerir 
para el diagnóstico de carcinoma intra-epitelial, así como para descartar las lesiones invasivas.

En nuestro medio tenemos que considerar un factor muy importante como es el de la posibilidad de control de la paciente.

Si esta paciente no puede ser motivo de controles adecuados, creemos que la mejor terapéutica es la preconizada y practicada por muchos autores deśde la iniciación de estos estudios, tales como Meigs, Te Linde (29), y que consiste en la histerectomía total con o sin coforectomía, según la edad de la pesiente.

Si la paciente se puede controlar, creemos que la edad continúa siendo el factor preponderante para la elección del tratamiento. Si la paciente es joven y con un futuro de fecundación, se debe practicar la conización del cervix continuando los controles con citología y biopsia.

Si la paciente es joven, pero no importa el futuro de fecundación, puede elegir entre la amputación del cervix y la histeiectomía total con conservación de ovarios.

Si la paciente se encuentra en la edad premenopáusica en adelante, el tratamiento de lesión si no hay riesgo quirúrgico es el de la histerectomía total con extirpación de ovarios. En el caso del riesgo quirúrgico se precticará la amputación del servix; en los casos en los cuales se practica la histerectomía total es aconsejable extirpar un buen sector de vagina, preferentemente con la prueba de tinción por el yodo.

Si la paciente, finalmente, se encuentra embarazada, es aconsejable llevar a término el embarazo y después del parto si el carcinoma persiste, llevar a cabo, según el caso, uno de los tratamientos antes mencionados.

\section{EIBLIOGRAFIA}

1. LOPEZ-ESCOBAR GUILLERMO--Diagnóstico precoz del cáncer (Citología y cáncer intra-epitelial). Repertorio de Medicina y Cirugía. Hospital de San Juan de Dios. Volumen IV. Número 5. Julio y agosto de 1949. Páginas 291-296.

1-A. LOPEZ-ESCOBAR GUILLERMO y LEAÑO S.-Lesiones distróficas y carcinoma in-situ del cervix. Revista Colombiana de Obstetricia y Ginecología. Volumen VIII. Número 5. Septiembre, cctubre de 1957.

2. LOPEZ-ESCOBAR G. et al.-Tratamiento del carcinoma del cervix uterino. Universitas. Volumen III. Número 11. 1951. Páginas 363-410.

3. LEAÑO FLOREZ S.-Displasias y carcinoma in-situ del cuello uterino. Tesis de la Universidad Javeriana. 1956.

4. FUNCK-BRENTANO P. et al--L'Epithelioma pavimenteux intra-epithelial du col uterin. Bull. de la Fed. Societes de Gyn. et Obst. Volumen IV. Número 1-bis. 1952. Páginas 80-144. 
5. R. MORICARD.-Diagnostic differentiel des etats dystrophiques et des epitehliomas pavimenteux cervicaux. Gynec. et Obstetrique. Volumen 51. Número 1. 1952. Páginas 1-22.

6. R. MORICARD.-Reflexions sur la definition du stade 0 des epitheliomas du col. uterin. Bull de la Fed. Societes de Gyec. et d'Obstetrique. Volumen 4. Número 5. 1952. Páginas 844-853.

7. FUNCK-BRENTANO P. y MORICARD R.-Metaplasie pavimenteuse benigne complete des glandes endo-cervicales et probleme du diagnostique differentiel avec L'epithelioma pavimenteux invasif du col. Eull de la Freb. Societes de Gynec. et d'Obstetrique. Volumen 4. Número 2. 1952. Páginas 213-217.

8. FUNCK-BRENTANO et al.-Diagnostic et traitement de l'Epithelima pavimentaux intra-epithelial du col. Uterin. Semaine des Hop. de París. A. 28. Número 71. Sep. 26/52. Páginas 1-10.

9. MARSH M. R. y HELLMAN L. M.-The value of an intensive pelvic cancer detection program. Surg. Clin. of North Am. 1953. Página 525. W. B. Saunders \& Co. Ed. Filadelfia.

10. MEIGS J. V. N.-Carter Monographs on Surgery. The Nelson and Sons Ed. N. Y. 1951.

11. DOUGLAS R. G. y FINN W. S.-Early recognition of ca. of cervix Surg. Clin. of North Am. 1953. Página 543. W. B. Saunders \& Co. Ed. Filadelfia.

12. EPPERSON J. W. et al.-The morphologial changes inthe cervix during pregnancy including intra-epithelial ca. Am. J. cf Obst. and Gynec. Volumen 61. Número 1. Jan./51. Páginas 50-61.

13. MURPHY E. J. y HERBUT P. A.-The uterine cervix cluring pregnancy. Am. J. Obst. \& Gynec. Volumen 59. Número 59. Número 2 Feb./50. Páginas 384-390.

14. GREENE et al.-Preinvasive carcinoma of the cervix during Pregnancy. Surg. Gyn. Obst. Volumen 96. Número 1. Jan./53. Páginas 71-81.

15. PECKHAM B. et al.-The relation of pregnancy to abnormalities of the cervical epithelium. Surg. Gyn. Obst. Volumen 99. Número 4. Oct./54. Páginas 401-412.

16. HELLMAN et al.-Some factors influencing proliferation cf reserve cells in human cervix. Am. J. Onst. \& Gyn. Volumen 67. April/54. Páginas 899-915.

17. NESBITT R. E. L.-Basal-cell hyperactivity of the cervix in pregnancy with post- partum follow-up. Obst. Gyn. Volumen VI. Número 3. Sep./55. Páginas 239-253.

18. GALVIN G. A. et al.-The significance of basal-cell hiperactivity in cervical biopsies. Am. J. Obst. \& Gynec. Volumen 70. Número 4. Oct./55. Páginas 808-821.

19. PEIGHTAL T. C. et al.-Conservative treatment of carcin:ma insitu of the cervix. Am. J. Obst \& Gynec. Volumen 69. Número 3. March./55. Página 547-557.

20. CARTER B. et al.-Clinical problems in stage 0 (intra-epithelial). Cancer of the cervix. Am. J. Obst. \& Gynec. Volumen 71. Número 3. March./ 56. Páginas 634-652. 
21. EASTMAN N. J. WILLIAMS.-Obstetrics. Appleton-Century crofts Inc. Ed. N. Y. 1956. Páginas 223-225.

22. FLUHMANN C. F.-Comparative studies of squamous metaplasia of the cervix uteri. Am. J. Obst. \& Gynec. Volumen 68. 1954. Página 1.447.

23. NOVAK E.-Gynecological and obsterical pathology W. B. Saunders Co. Ed. Filadelfia. 1940 .

24. NOVAK E.-Textbook of gynecology. The Wuilliams \& Wilkins Co. Ed. 1944.

25. HERTIG A. T. y MANSELL H.-Meigs and Sturgis progress in gynecology. Volumen III. Grune \& Stratton Ed. N. Y. 1957.

26. NESBITT R. E. L. y HELLMAN L. M.-The histopathology and cytology of the cervix in pregnancy. Surg. Gynec. \& Obst. Volumen 94. 1952. Página 10.

27. SIEGLAR EDWARD E.-Microdiagnosis of carcinoma in-situ of the uterine cervix. A comparative study of pathologit's diagnoses.

28. REAGAN, J. W., and HICHS, D. J.-A study on in situ and squamous cell cancer of the uterine cervix. Cancer. 6: 1.200. 1953.

29. MEIGS JOE V.-Carcinoma in-situ of the cervix. Monograph on surgery. Thomas Nelson \& Son. 1951. Toronto. N. Y. Edinburgh.

30. MARSH M. HELLMAN L.-The value of an intensive pelvic cáncer detection program. With special reference to intraepithelial pelvic cancer Surg. Clin. North America, 33: 525. 1953.

31. CAMPOS J. SOIHET S.-Histologic changes in the uterine cervix during pregnancy and the diagnosis of carcinoma in-situ. Surg. Gyn. \& Obst. 4: 104. 1956.

32. MEMOIR MARSH and PATRICK FITZGERALD.-Carcinoma insitu of the human uterine cervix in pregnancy. Cancer 9: 1.195. 1956.

33. GALVIN GERALD et al.-Clinical relationship of carcinoma in-situ and invasive carcinoma of the cervix. J. Am. Med. Ass. Volumen 149. Número 8. June. 1952.

34. HARNOLDO CALVO NUNEZ y THEODORE Winship.-Carcinoma in-situ del cervix. Revista de la Facultad de Medicina. Universidad Nacional, Bogotá. 19: 319. 1953.

35. BAYARD CARTER, W. KENNETH CUYLER, LUISE A. KUFMANN, WALTER L. THOMAS, ROBERT N. CREADICK, ROY T. PARKER. CHARLES E. PEETE, Jr. and WALTER B. CHERNY.-Clinical problems in stage 0 (intraephitelial). Cancer of the cervix. Am. J. Obst. \& Gyn. 71: 634, 1956.

36. JORDAN A. GERMAN.-El problema del carcinoma intra-epitelial del cuello uterino. Universitas. Número 4. 1953. Bogotá.

37. PETERSEN.-Spontaneous course of cervical precancerus conditions. Am. Jour. Obst. \& Gyn. 72. 1.063, 1.071. 1956.

38. RAWSON, KNOBLICH. A.-Clinicopathologyc study of 56 cases showing atypical epithelial changes of the cervix uteri. Am. Jour. Obst. Gyn. 73. 120, 126, 1957.

39. SLATE, PURVIX, MARTIN, JOHN W. MERRITT.-The value of routine cervical smears in the detection onf incipient cervical carcinoma in pregnant women. Am. J. Obstetrics \& Gyn. 74: 344. 1957.

40. BAKER, HAWKS.-The prognostic significance of glandular involvement in cold knife conization biopsies in carcinoma in-situ of the uterine cervix. Am. J. Obst. \& Gyn. 73. 1.266. 1957. 


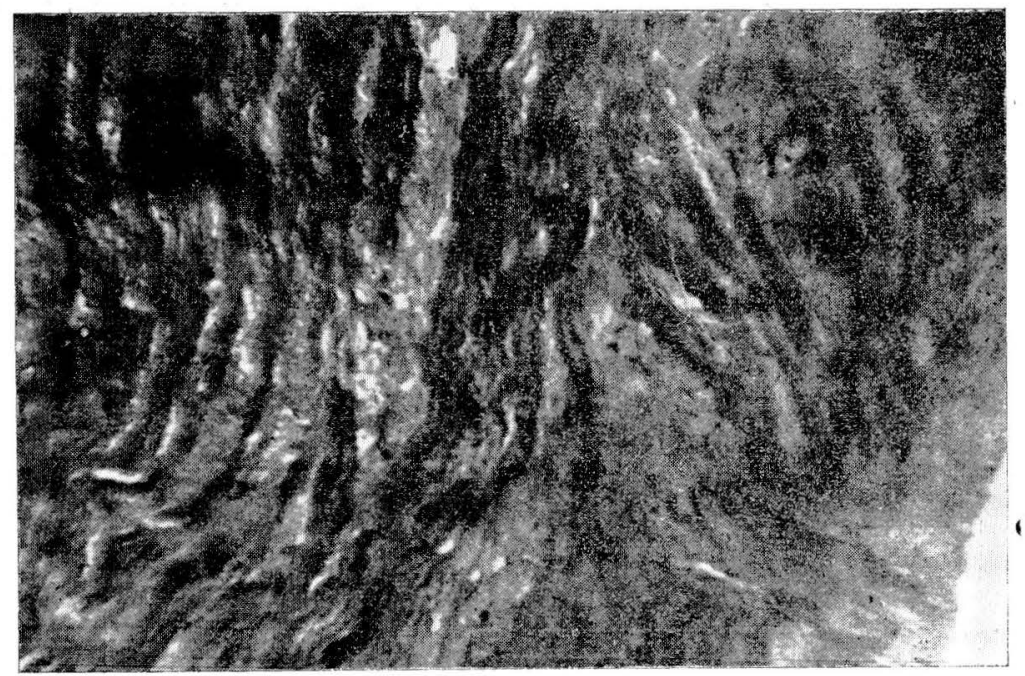

FIGURA NUMERO I.-Cervix de una niña de cinco añ ss (Hematoxilina-Eosina) .

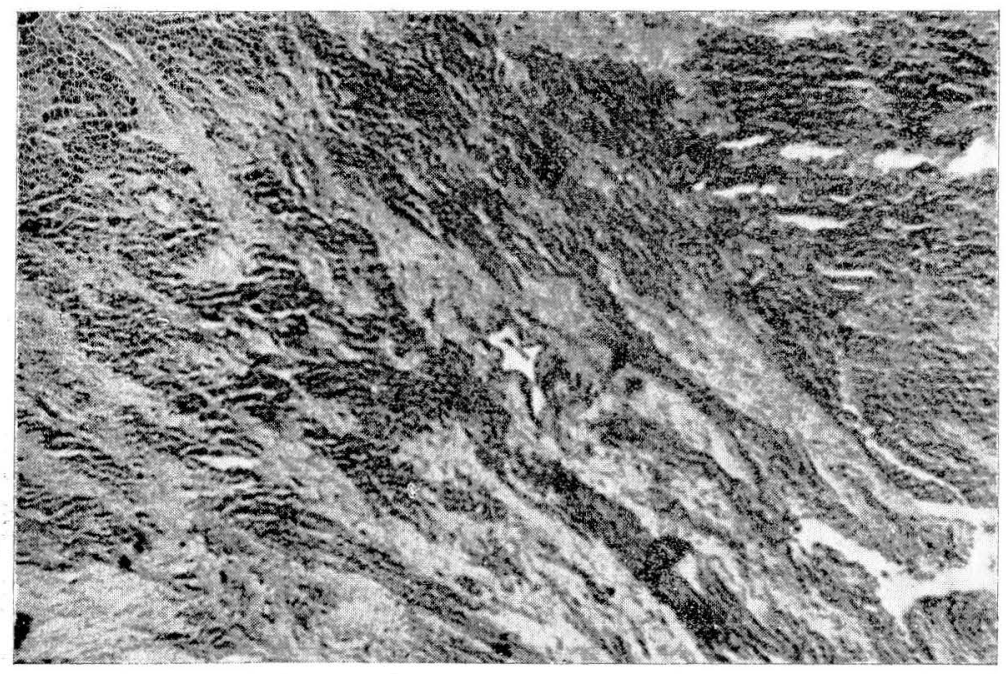

FIGURA NUMERO I-A.-Cervix de una niña de cinco años (Goma Iodada). No se demuestra glucógeno. 


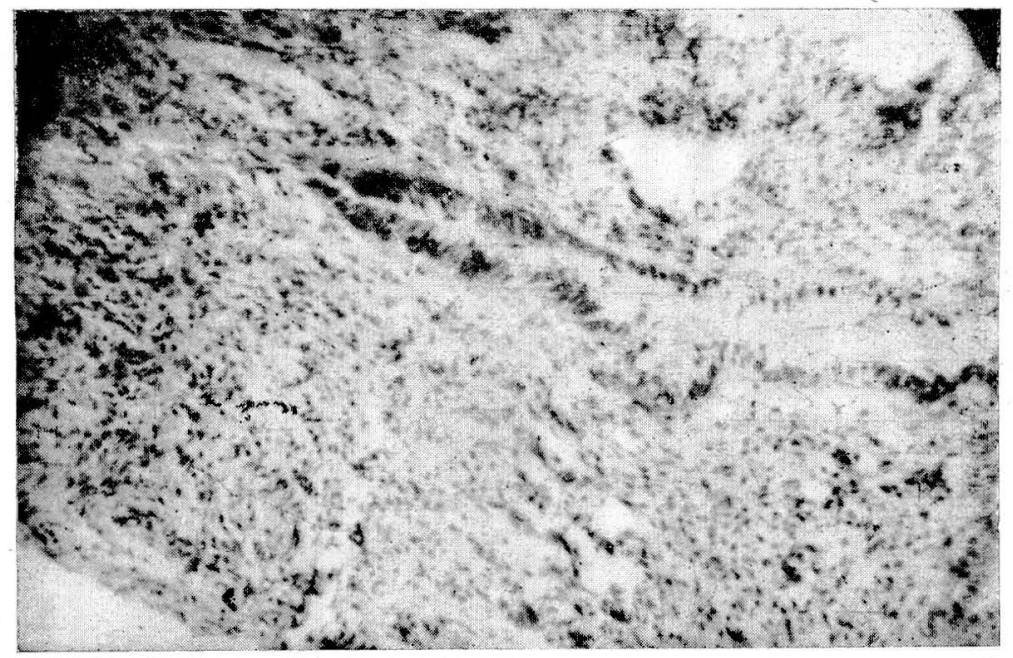

FIGURA NUMERO I-B.-Cervix de una niña de cinco años. Esbozo de glándula endocervical.

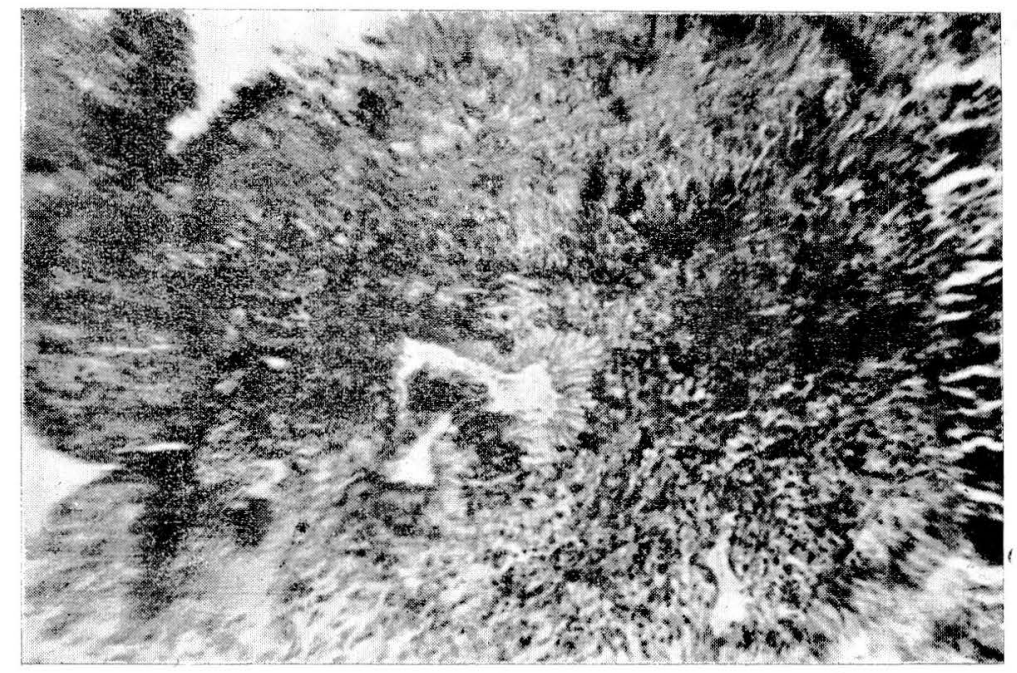

FIGURA NUMERO II.-Metaplasia cervical (Hematoxilina-Eosina) (Protocolo número 11.636). Nótese la glándula en el centro. 


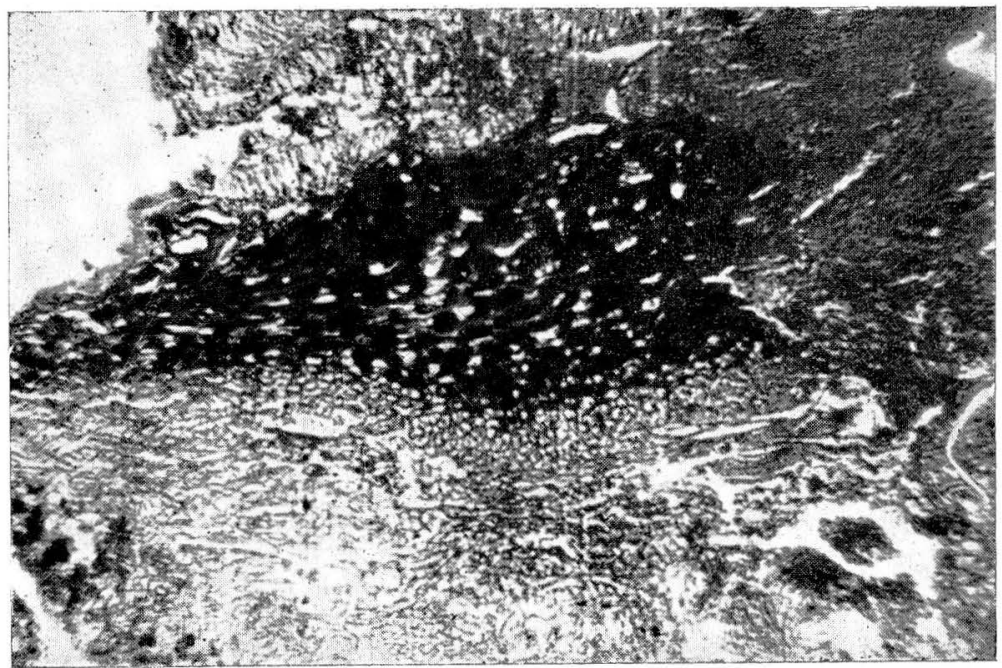

FIGURA NUMERO II-A.-Metaplasia cervical (Goma Iociada) (Protocolo número 11.636). La parte oscura en el centro corresponde a las células coloreadas con la goma iodada del epitelio pavimentoso dentro de una glándula.

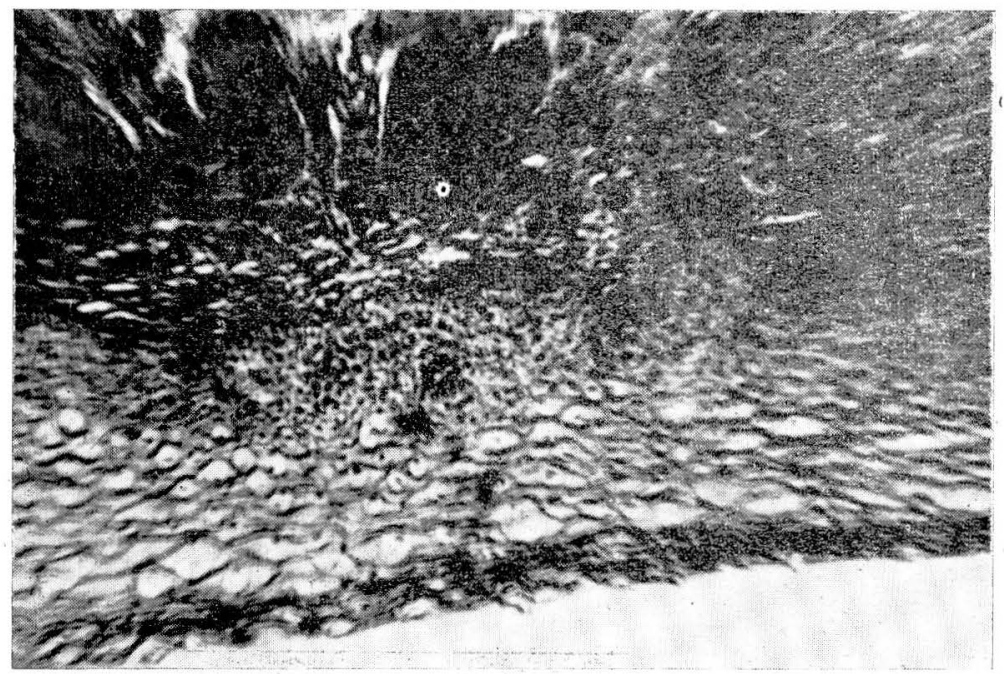

FIGURA NUMERO III.-Leucoplasia cervical (Hematoxilina-Eosina) (Protocolo número 11.021). 


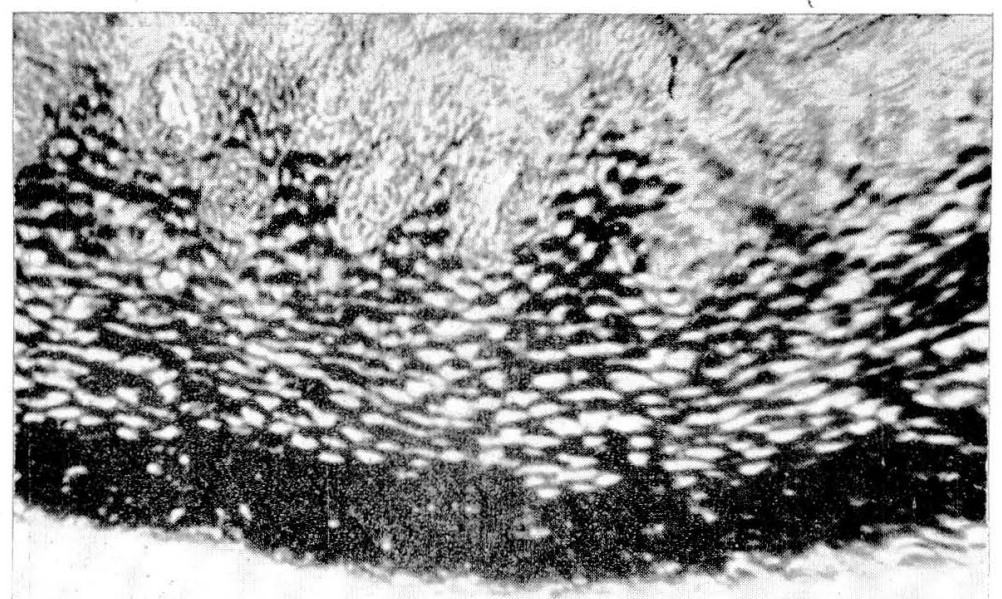

FIGURA NUMERO III-A.-Leucoplasia cervical (Goma Iodada) (Protocolo número 11.021). Existe abundante glucógeno que corresponde a la porción oscura de las células, difícil de hacer aparente en la fotografía en blanco y negro.

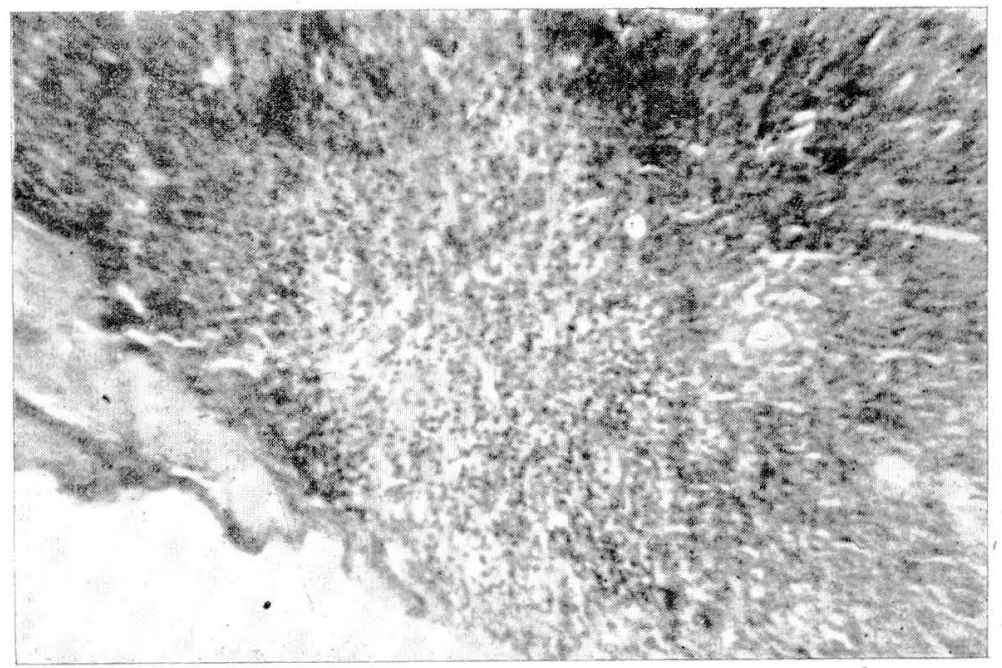

FIGURA NUMERO IV.-Hiperplasia y queratosis exocervical con tricomoniasis (Hematoxilina-Eosina) (Protocolo número 11.605). 


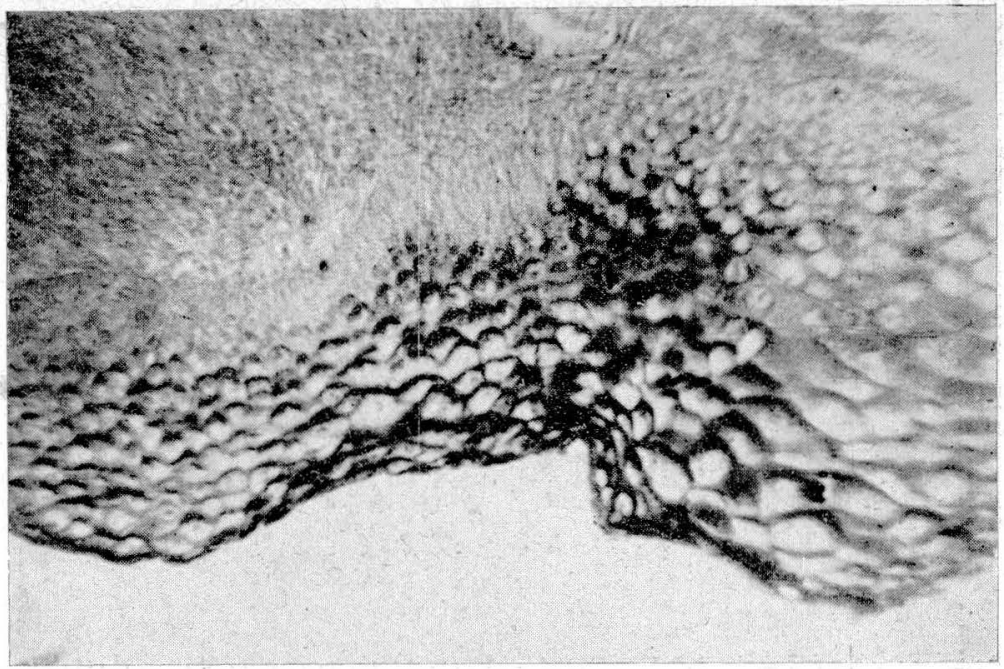

FIGURA NUMERO IV-A.- Hiperplasia y queratosis exocervical con tricomoniasis (Goma Iodada) (Protocolo número 11.605),

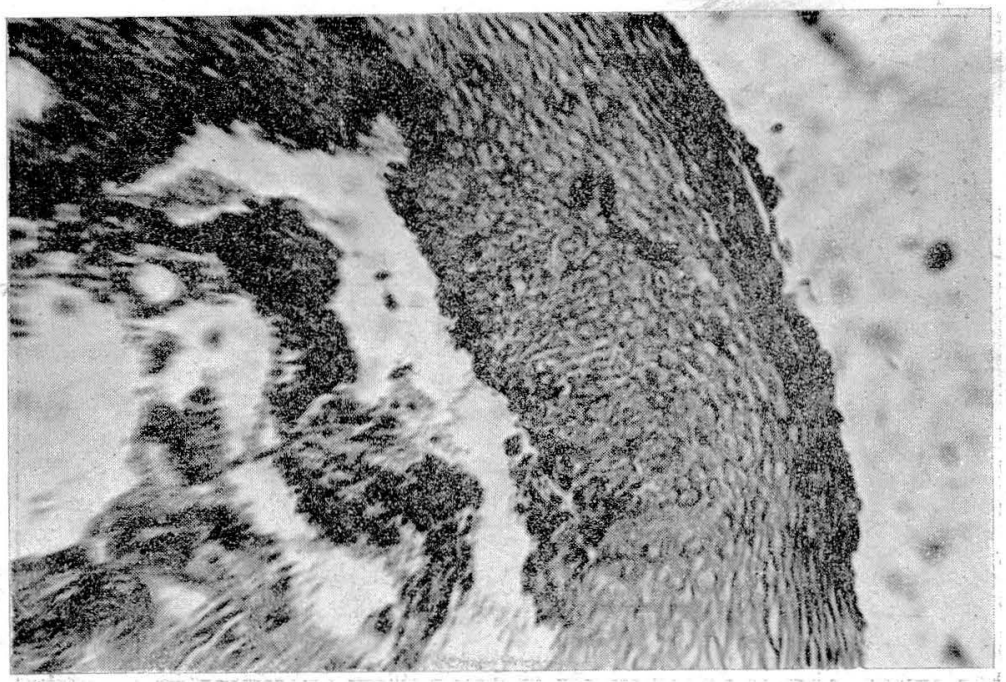

FIGURA NUMERO V.-Hiperplasia exocervical (Hematoxilina-Eosina) (Protocolo número 11.370). 


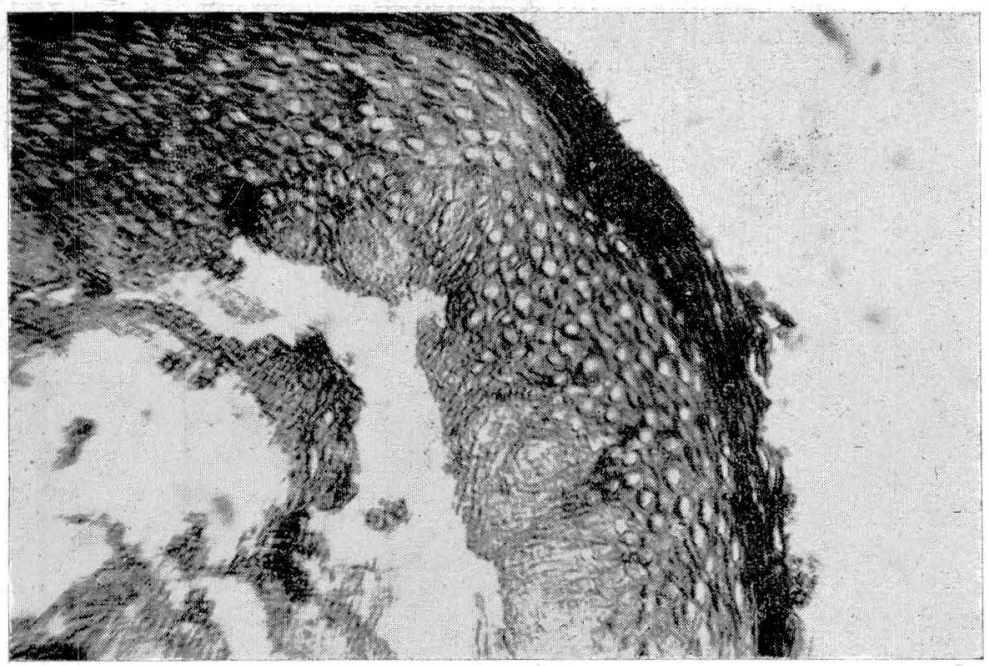

FIGURA NUMERO V-A.-Hiperplasia exocervical (Goma Iodada) (Protocolo número 11.370). Ausencia de glucógeno.

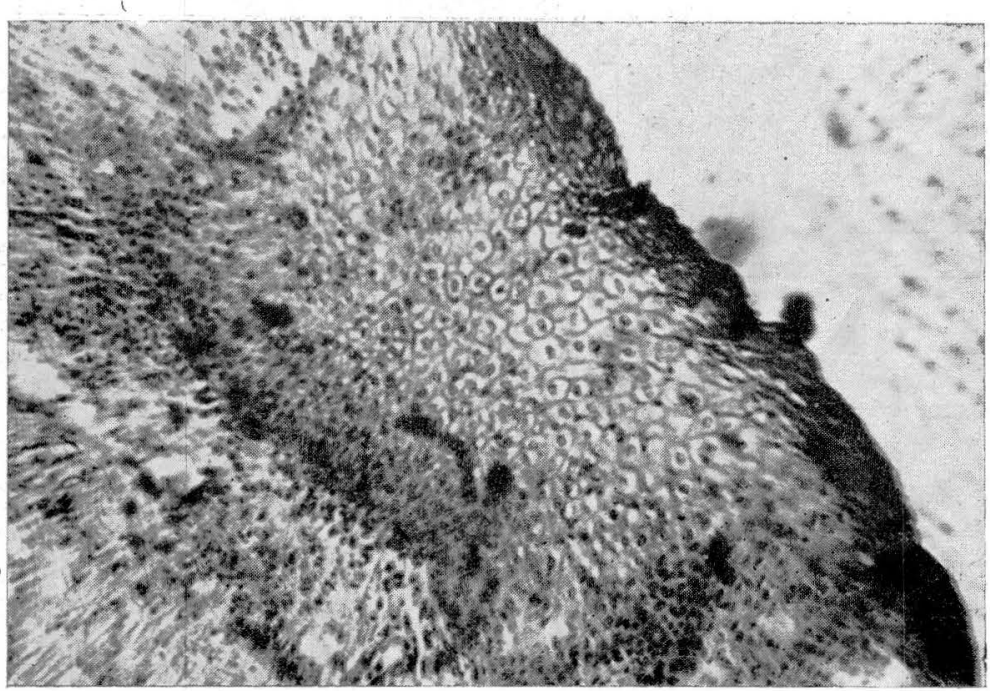

FIGURA NUMERO VI.-Hiperplasia y cervicitis (Hematoxilina-Eosina) (Protocolo número 11.265). 


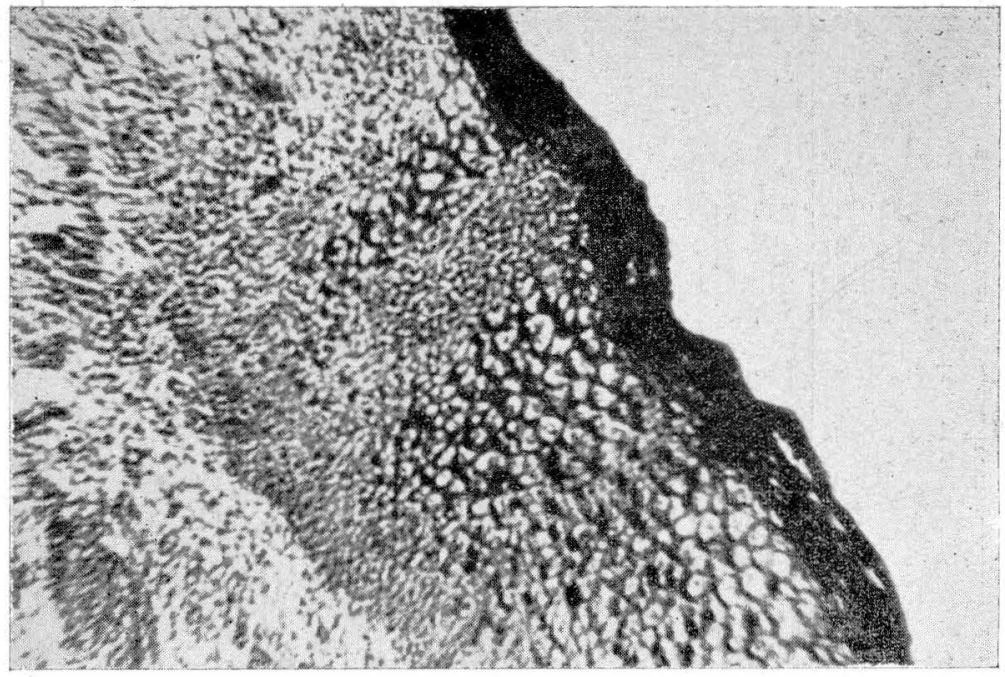

FIGURA NUMERO VI-A.-Hiperplasia y cervicitis (Goma Iodada) (Protocolo número 11.265). Glucógeno ausente en unas zonas, en otras abundante.

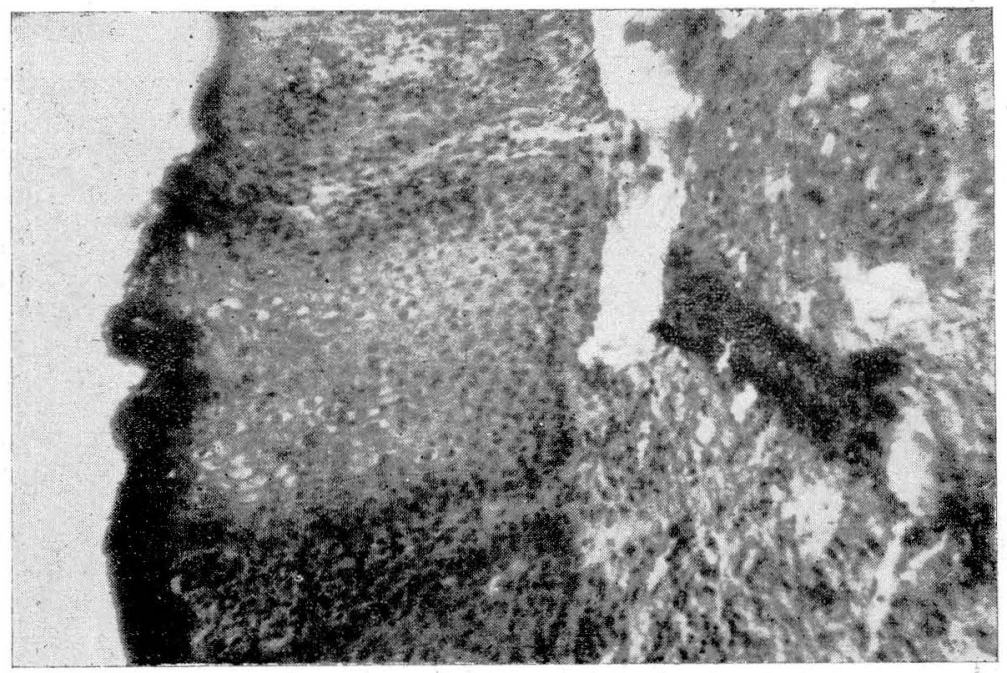

FIGURA NUMERO VII.-Hiperplasia glandular moderada (Hematoxilina-Eosina). Existe también hiperplasia epitelial concomitante. El corte histológico está bastante dañado, pero en general los orificios corresponden a glándulas. 


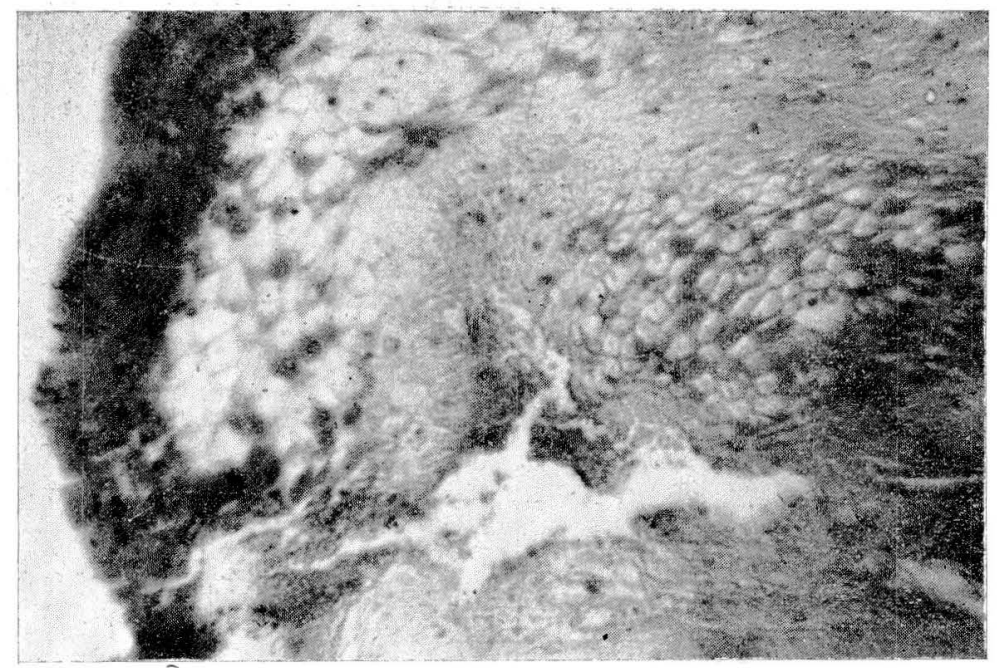

FIGURA NUMERO VII-A.-Hiperplasia glandular moderada (Goma Iodada) .

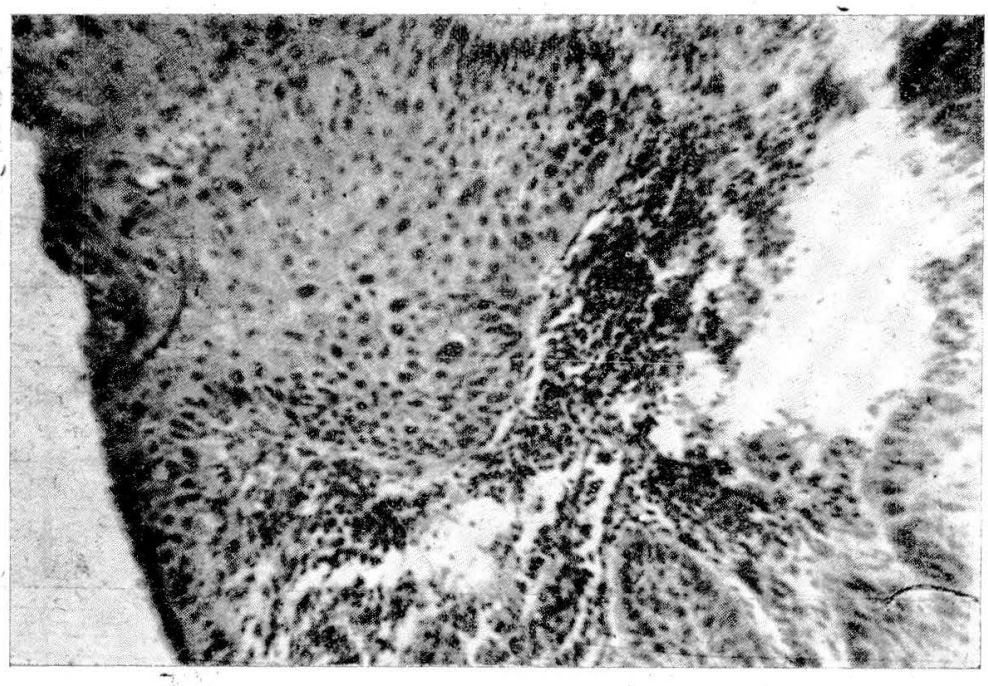

FIGURA NUMERO VIII.-Cervix en embarazo (Hematoxilina-Eosina). Nótese la hiperactividad basal ligera. 


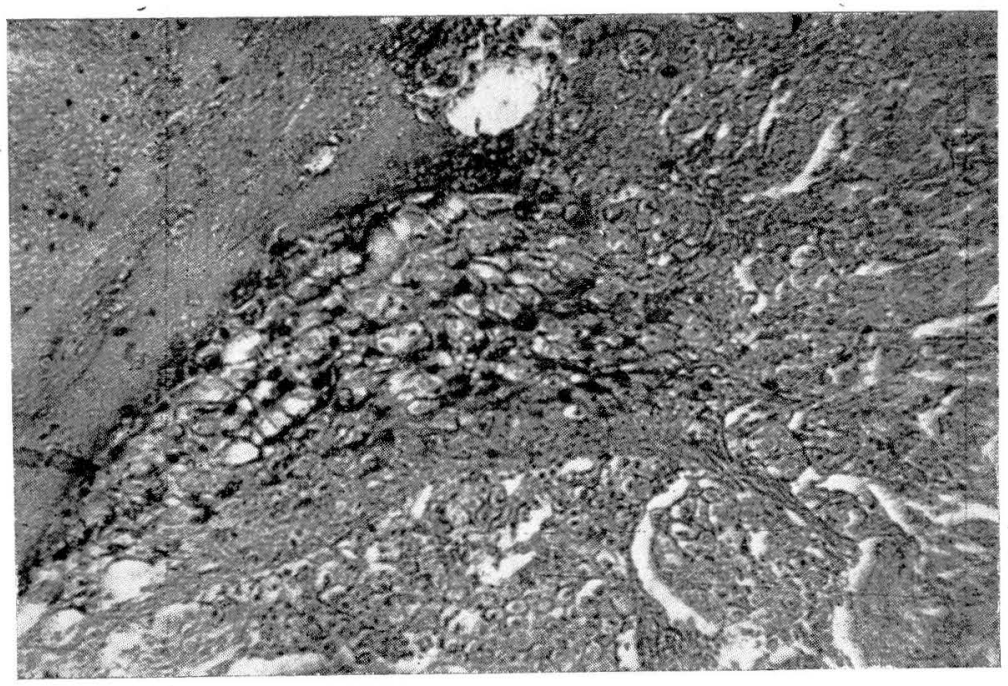

FIGURA NUMERO VIII-A.-Cervix en embarazo (Goma Iodada).

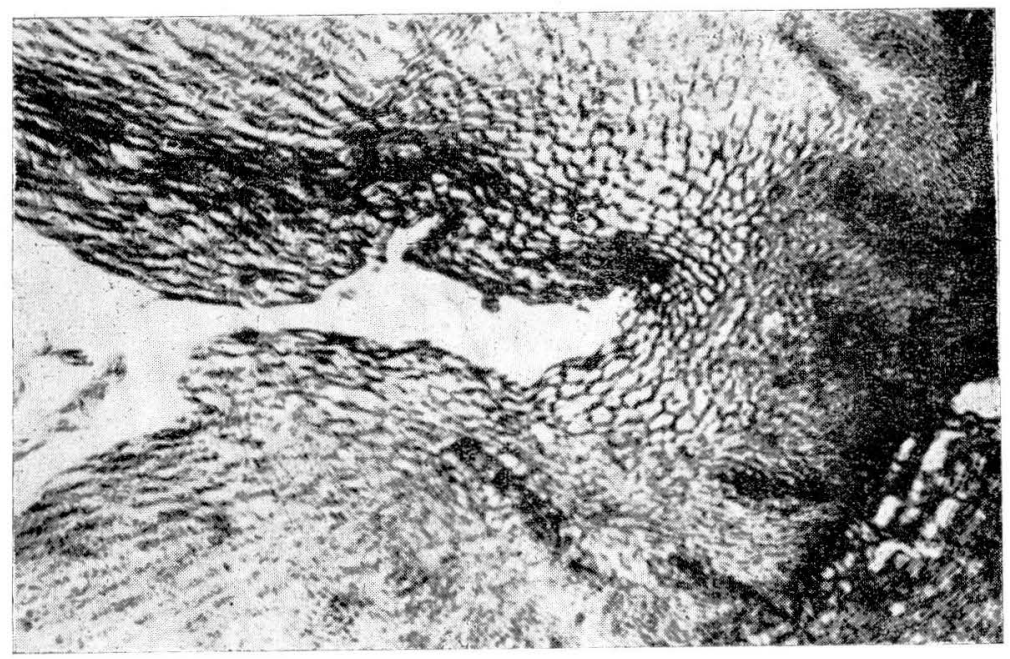

FIGURA NUMERO IX.-Ca. intraepitelial cervical (HematoxilinaEosina) (Protocolo número 11.416). Nótese la transf zrmación graclual entre el epitelio normal en los dos tercios inferiores y el ca. intraepitelial en el tercio superior. La fotografía en blanco y negro no es tan diciente com ja de color original. 


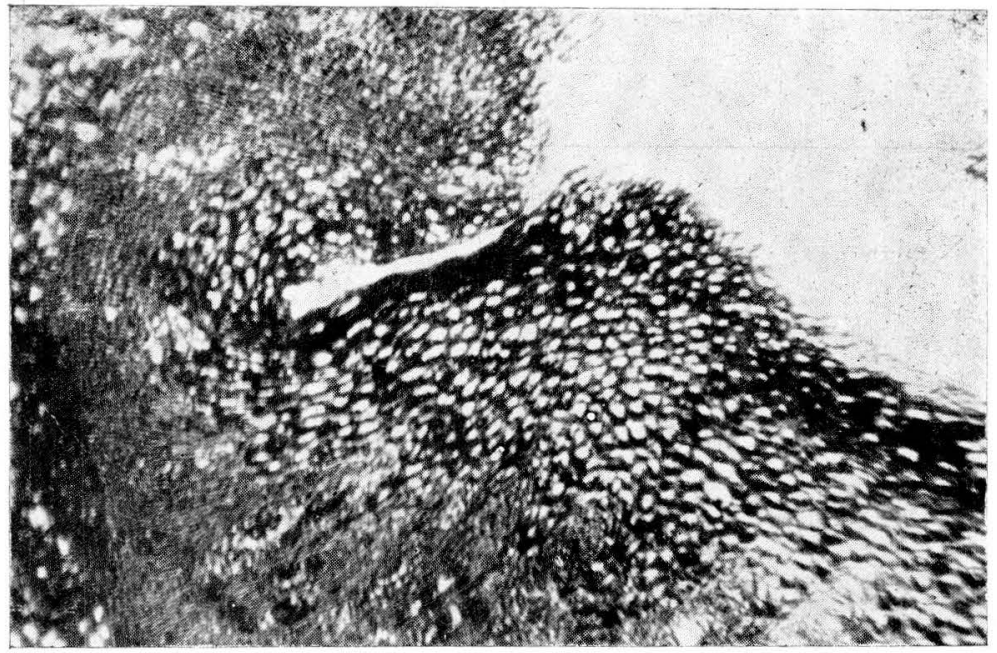

FIGURA NUMERO IX-A.-Ca. intraepitelial cervical (Goma Iodada) (Protccolo número 11.416). La ausencia de glucógeno es bien visible en la fotografía en color original (conocidas son las dificultades para la publicación de fotografías en color entre nosotros). 